\title{
VARIABILIDADE ANUAL E MENSAL DA CHUVA E DA TEMPERATURA DO AR NO MUNICÍPIO DE RESENDE, RIO DE JANEIRO
}

\author{
GOIS, Givanildo de - givanildogois@gmail.com \\ Universidade Federal Fluminense / UFF \\ FREITAS, Welington Kiffer de - wkifferpgtauff@gmail.com \\ Universidade Federal Fluminense / UFF \\ TERASSI, Paulo Miguel de Bodas - pmbterassi@usp.br \\ Universidade de São Paulo / USP \\ OLVEIRA-JÚNIOR, José Francisco de - jose.junior@icat.ufal.br \\ Universidade Federal do Alagoas / UFAL \\ PORTZ, Adriano - aportz@id.uff.br \\ Universidade Federal Fluminense / UFF
}

\begin{abstract}
RESUMO: Os objetivos deste estudo são: i) avaliar a variabilidade anual e mensal da chuva e temperatura do ar e ii) quantificar as componentes do balanço hídrico climatológico no município de Resende (RJ). Os dados mensais de chuva e de temperatura foram obtidos pelo Instituto Nacional de Meteorologia para o período de 1995 a 2017. As séries temporais possuíam falhas e foram preenchidas pelos pacotes do software ambiente $R$, com base na estatística descritiva e exploratória aplicada na série temporal. Os coeficientes de variação foram altamente variáveis ao longo da série temporal. As menores diferenças pluviométricas anuais foram observadas nos percentis dos quantis de $25 \%$ e $50 \%$ da média e mediana, seguido das diferenças superior à média, nos percentis de $75 \%$ a $100 \%$ dos quantis. Verificou-se um aumento da temperatura anual nos percentis dos quantis de $25 \%$ e $50 \%$. O balanço hídrico climatológico mostrou uma distribuição irregular na chuva mensal, com duas estações bem definidas: a estação chuvosa inicia-se em setembro, com o maior excedente hídrico em janeiro e dezembro, e o período com déficit hídrico ocorre de abril e agosto. A variação da temperatura média anual foi de $18,28^{\circ} \mathrm{C}$ a $25,76^{\circ} \mathrm{C}$ e a chuva média anual de $1.528,48 \mathrm{~mm}$.
\end{abstract}

PALAVRAS-CHAVE: variáveis climáticas, parâmetros estatísticos, balanço hídrico climatológico, quantis.

ANNUAL AND MONTHLY VARIABILITY OF RAINFALL AND AIR TEMPERATURA IN THE MUNICIPALITY OF RESEND, RIO DE JANEIRO

ABSTRACT: The objectives of this study are: i) to evaluate the annual and monthly variability of rainfall and air temperature and ii) to quantify the components of the climatological water balance, in the municipality of Resende (RJ). The monthly pluviometric data and temperature were obtained from INMET between 1995 and 2017. The time series had faults and were filled by the software packages $R$ environment, based on the descriptive and exploratory statistics applied in the time series. The coefficients of variation were highly variable throughout the time series. The lowest annual pluviometric differences were $25 \%$ and $50 \%$ of the mean and median quantiles, followed by the above-average differences, in the percentiles of $75 \%$ to $100 \%$ of the quantiles. There was an annual temperature increase in quantum percentiles of $25 \%$ and $50 \%$. The climatic water balance showed an irregular distribution in the monthly rainfall, with two seasons: the rainy season begins in September, with the largest water surplus in January and December, and the period with water deficit was in April and August. The 
mean annual temperature range was $18.28^{\circ} \mathrm{C}$ at $25.76^{\circ} \mathrm{C}$ and the average annual rainfall was $1,528.48 \mathrm{~mm}$.

KEYWORDS: climatic variables, statistical parameters, climatological water balance, quantiles

\section{INTRODUÇÃO}

Recentemente, muito tem se discutido, tanto no meio político como acadêmico, sobre as mudanças climáticas e suas consequências em termos social, ambiental e econômico, sendo consenso que o clima no planeta nem sempre ocorreu da forma atual. Porém, muitas questões vêm sendo abordadas, dentre elas, se determinadas regiões poderão ser atingidas e em que escala temporal ocorrerão (MINUZZI, 2010; MINUZZI et al. 2011; ÁVILA et al., 2014).

Os modelos climáticos globais (MCG) atuais estimam que até o fim do século XXI a temperatura no planeta poderá aumentar entre $2,0^{\circ} \mathrm{C}$ a $4,8^{\circ} \mathrm{C}$, reservando ao Brasil elevada vulnerabilidade aos possíveis efeitos destas alterações (IPCC, 2013; CIRINO et al., 2014). Além do Intergovernmental Panel on Climate Change (IPCC), muitos cientistas apontam que o aquecimento global vem aumentando devido à influência antrópica, em escala extremamente provável ( $95 \%$ de probabilidade), devido ao aumento das emissões de gases do efeito estufa (GEE), principalmente, o gás carbônico $\left(\mathrm{CO}_{2}\right)$, o metano $\left(\mathrm{CH}_{4}\right)$ e o óxido nitroso $\left(\mathrm{N}_{2} \mathrm{O}\right)$, resultantes da queima de combustíveis fósseis, desmatamento, queimadas, uso do solo e outras atividades antrópicas (IPCC, 2013).

Dentre os atributos climáticos, a precipitação pluvial é uma variável fundamental para o funcionamento e a manutenção dos ecossistemas no planeta, especialmente nas regiões tropicais. O conhecimento dos padrões de chuvas contribui para o planejamento de diversas atividades humanas: agropecuária, geração de energia, aviação, obras hidráulicas, etc. É importante monitorar eventos extremos de chuva, responsáveis por catástrofes (deslizamentos e enchentes), que vem trazendo sérios impactos ambientais, econômicos e sociais (MELLO et al., 2009; SALTON et al., 2016).

Por sua vez, frequentemente, as estimativas de temperatura e preciitação pluvial têm sido realizadas não somente para a compreensão destes elementos climáticos isolados, mas normalmente como parâmetro para quantificar a disponibilidade hídrica a partir do balanço hídrico climatológico $(\mathrm{BHC})$. O BHC de uma região permite avaliar a variação temporal da quantidade de água armazenada no solo (superficial e subterrânea) e dos respectivos fluxos (chuva, escoamento e evapotranspiração - ET), o que permite chegar a resultados importantes sobre o regime hidrológico da região e das possibilidades de utilização dos recursos hídricos a nível local. Pereira (2005) afirma que o BHC é um sistema contábil de água do solo e resulta da aplicação do princípio de conservação da massa em um volume de solo.

Situado no sul do estado do Rio de Janeiro, o município de Resende está localizado entre as encostas da Serra do Mar e da Serra da Mantiqueira, sendo frequente a ocorrência de chuvas orográficas (ANDRÉ et al., 2008; BRITO et al., 2016; FARIAS et al., 2017; SOBRAL et al., 2018). A região apresenta característica de transição entre os domínios tropical e subtropical (ÁLVARES et al., 2013; DUBREUIL et al., 2017), com topografia complexa e a influência dos deslocamentos de constante deslocamentos dos sistemas frontais (SF) e, 
especialmente no verão, com a formação da Zona de Convergência do Atlântico Sul (ZCAS), são fatores responsáveis por chuvas abundantes (SANT'ANNA NETO, 1994; NERY et al., 2002; REBOITA et al., 2010).

O ciclo do café, praticado no século XIX, resultou em importantes transformações na paisagem da região, com reflexos na alteração no regime de distribuição de chuvas, que historicamente era representado por um padrão bem distribuído ao longo do ano (FIGUEIRÓ; COELHO NETTO, 1993). No século $X X$, a pecuária extensiva promoveu a compactação do solo e a contaminação de córregos, além do desmatamento de grandes áreas. Depois da segunda metade do século $X X$, os impactos ambientais continuaram se amplificando em toda a região, dessa vez, resultantes dos processos de urbanização e industrialização, também deixando seus reflexos sobre o solo e vegetação, e, consequentemente, influenciando a temperatura e o padrão de chuvas em escala local (GAMA BENTES, 2010).

Baseado no exposto, os objetivos principais deste estudo são: i) avaliar a variabilidade anual e mensal da chuva e temperatura do ar e ii) quantificar as componentes do balanço hídrico climatológico no município de Resende (RJ).

\section{MATERIAL E MÉTODOS}

\subsection{LOCALIZAÇÃO E CARACTERIZAÇÃO DA ÁREA DE ESTUDO}

O município de Resende situa-se na região do Governo do Médio Paraíba do estado do Rio de Janeiro (ERJ), na região Sudeste do Brasil (Figura 1). Conforme a classificação de Köppen (1948), o clima de Resende é tropical com estação seca ("Aw"), a temperatura média anual é em torno de $22,4^{\circ} \mathrm{C}$, com média mínima de $18,3^{\circ} \mathrm{C}$ em julho e média máxima de $25,8^{\circ} \mathrm{C}$ no mês de janeiro. Os maiores registros de chuvas ocorrem na estação de verão, com médias superiores a $200 \mathrm{~mm}$ entre novembro e dezembro, e com a significativa redução das chuvas entre junho a agosto, nos quais as médias são inferiores a $30 \mathrm{~mm}$ (Figura 2).

Estas características de concentração de chuvas no período de primavera e verão é condizente com o observado por Keller Filho et al. (2005) e Reboita et al. (2010) para o clima tropical do Brasil central, no qual mais de $70 \%$ das chuvas se concentram nas estações supracitadas. Entretanto, como se trata de uma região de transição de clima tropical e subtropical, observa-se a diminuição significativa das médias térmicas, especialmente entre junho e agosto, período no qual as médias mensais são inferiores a $20^{\circ} \mathrm{C}$. A variação sazonal da temperatura identificada para Resende está próxima ao observado para estes setores do território nacional (ÁLVARES et al., 2013; DUBREUIL et al., 2017) e em áreas próximas a este município no estado de São Paulo (ROLIM et al., 2007), condições próprias às transições climáticas, conforme apontam Silva et al. (2006). 


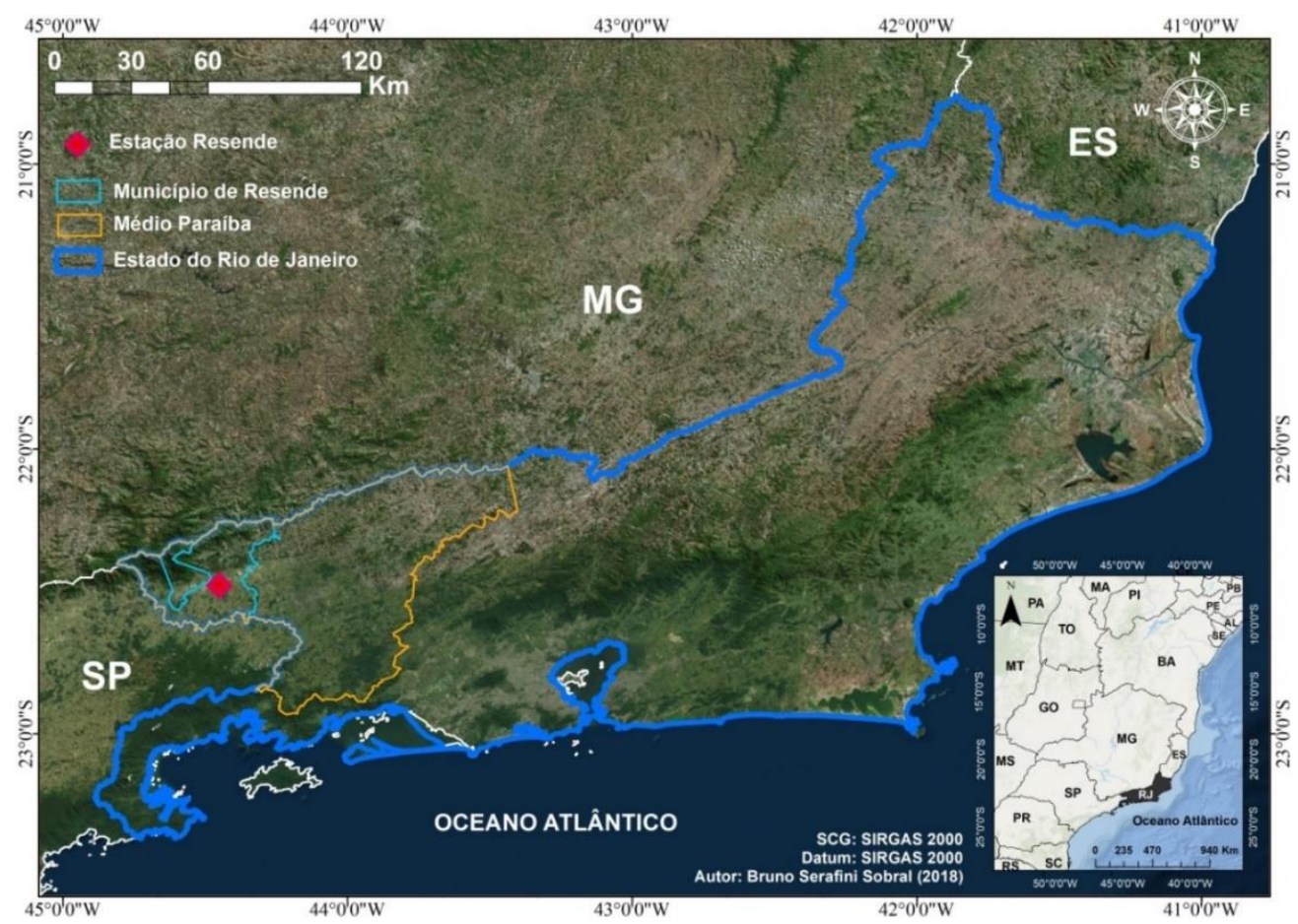

Figura 1 - Estado do Rio de Janeiro e localização da estação meteorológica automática de Resende, região do Médio Paraíba - Rio de Janeiro, Brasil.

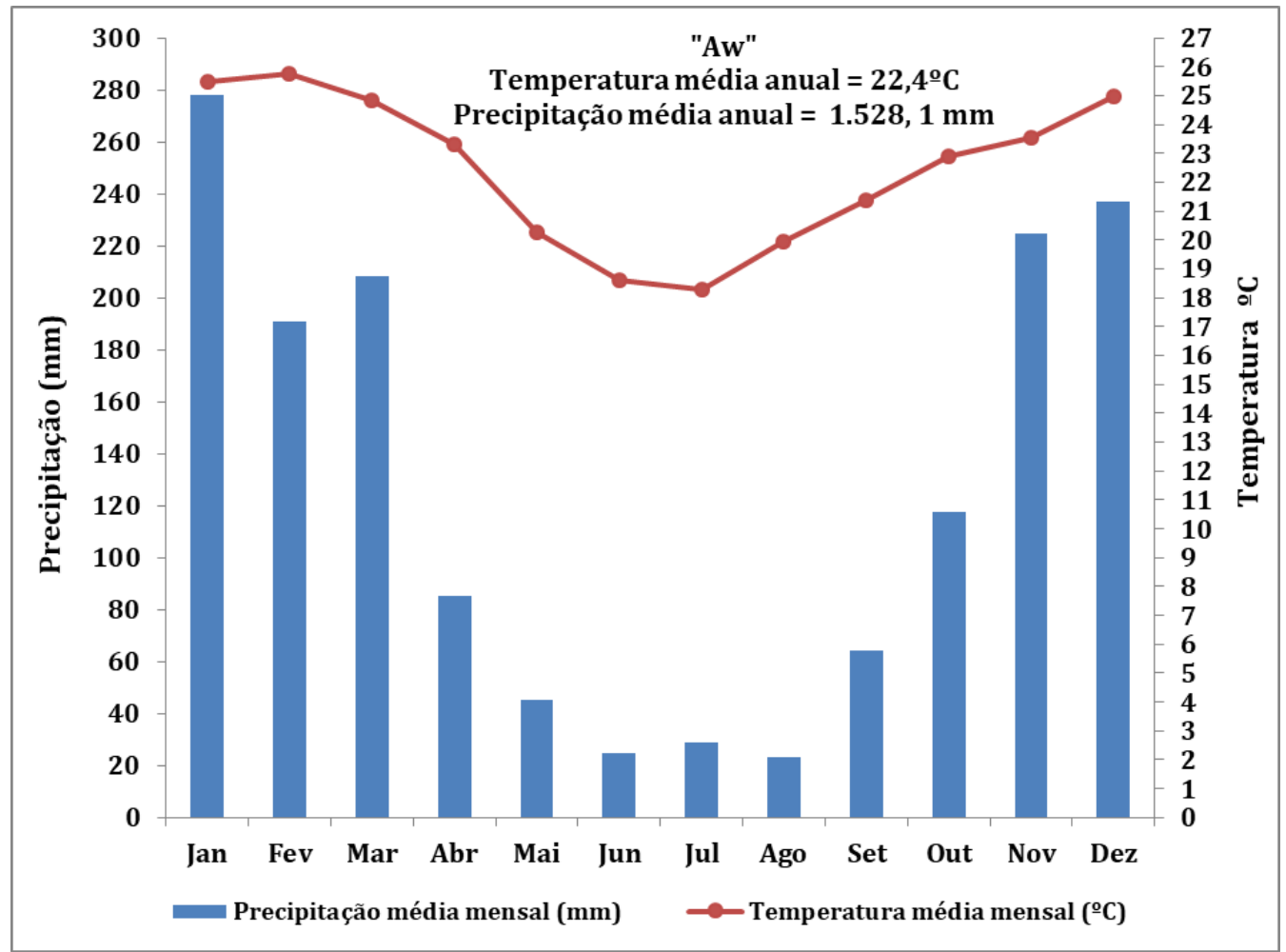

Figura 2 - Climograma e classificação climática de Köppen (1948) para Resende (RJ). 


\subsection{SÉRIE TEMPORAL CLIMÁTICA E PREENCHIMENTOS DE FALHAS}

Os dados de chuva e temperatura do ar utilizados neste trabalho foram disponibilizados pelo Instituto Nacional de Meteorologia (INMET), que possuem uma estação meteorológica automática (EMA) em Resende, e que abrangem o período de janeiro de 1995 a dezembro de 2017. A EMA de Resende está situada a uma altitude de $439 \mathrm{~m}$ e nas coordenadas de $22,45^{\circ} \mathrm{S}$ e $44,44{ }^{\circ} \mathrm{W}$.

Para verificar o percentual (\%) de falhas de dados de chuva e temperatura do ar diárias e o seu respectivo preenchimento, foram utilizados os pacotes "mstats" e "mtsdi" no software "R" versão 3.4.3 (R DEVELOPMENT CORE TEAM, 2017). Em que, o pacote "mstats" verifica o percentual das falhas (dados faltantes = missing), que posteriormente foram transformados em valores mensais. O cálculo dos missing é feito via linhas de comando, onde cada função calcula a proporção de observações ausentes em um determinado conjunto de dados por matriz (linhas e colunas).

As séries temporais diárias pluviométricas e de temperatura do ar que apresentam falhas foram preenchidas com auxílio do pacote "mstats" e, posteriormente, a série foi transformada em uma série temporal mensal, e contabilizada o percentual de dados faltantes mensais a partir do pacote "mtsdi" no software "R" versão 3.4.3 (R DEVELOPMENT CORE TEAM, 2017).

Após a contabilização das falhas, iniciou-se o processo de imputação dos dados para as respectivas variáveis chuvas e temperaturas do ar, através do pacote "mtsdi". O método de imputação de dados consiste em uma função genérica, onde o conjunto de dados é transformado através da função spline, que suaviza a série temporal. Estes procedimentos foram realizados das nas seguintes etapas: interação de dados (1), extração de dados de imputação (2) e imputação (3), conforme descrito a seguir:

$\mathrm{df}=\mathrm{a} ; \mathrm{B}=\mathrm{a} ; \mathrm{C}=\mathrm{a} ; \mathrm{D}=\mathrm{a} ; \mathrm{E}=\mathrm{a} ; \mathrm{F}=\mathrm{a} ; \mathrm{G}=\mathrm{a} ; \mathrm{H}=\mathrm{a} ; \mathrm{I}=\mathrm{a} ; \mathrm{J}=\mathrm{a} ; \mathrm{L}=\mathrm{a} ; \mathrm{M}=\mathrm{a} ; \mathrm{N}=\mathrm{a} ; \mathrm{O}=\mathrm{a} ; \mathrm{P}=\mathrm{a} ; \mathrm{Q}=\mathrm{a} ; \mathrm{R}=\mathrm{a} ; \mathrm{S}=\mathrm{a} ; \mathrm{T}=\mathrm{a} ; \mathrm{U}=\mathrm{a} ; \mathrm{V}$ $=a ; X=a ; Z=a$

$(\mathrm{f}<-\sim \mathrm{C} 1+\mathrm{C} 2+\mathrm{C} 3+\mathrm{C} 4+\mathrm{C} 5+\mathrm{C} 6+\mathrm{C} 7+\mathrm{C} 8+\mathrm{C} 9+\mathrm{C} 10+\mathrm{C} 11+\mathrm{C} 12+\mathrm{C} 13+\mathrm{C} 14+\mathrm{C} 15+\mathrm{C} 16+\mathrm{C} 17+\mathrm{C} 18$ $+\mathrm{C} 19+\mathrm{C} 20+\mathrm{C} 21+\mathrm{C} 22+\mathrm{C} 23)$

IMP=mnimput $(f$, dados1,eps=1e-3,ts=TRUE, method="spline",sp.control=list $(d f=c(A, B, C, D, E$, $\mathrm{F}, \mathrm{G}, \mathrm{H}, \mathrm{I}, \mathrm{J}, \mathrm{L}, \mathrm{M}, \mathrm{N}, \mathrm{O}, \mathrm{P}, \mathrm{Q}, \mathrm{R}, \mathrm{S}, \mathrm{T}, \mathrm{U}, \mathrm{V}, \mathrm{X}, \mathrm{Z})$ ))

Em que, $a$ = número de interações para as variáveis chuva e temperatura do ar; $d f=$ interações para a chuva e temperatura em 24 horas; $f=$ função empírica das variáveis chuva e temperatura do ar em 24 horas; IMP = método de imputação usando a spline.

\subsection{CONSISTÊNCIA DOS DADOS}

A qualidade dos dados de chuva e temperatura do ar foi avaliada via análise de consistência de dados por meio da aplicação da estatística descritiva. Os parâmetros obtidos foram a média $(\bar{x})$, a mediana $\left(M_{d}\right)$, o desvio padrão $\left(D_{p}\right)$, valor máximo $\left(V_{M}\right)$ e mínimo $\left(V_{N}\right)$, amplitude total $\left(A_{t}\right)$, limites superiores 
$\left(L_{s}\right)$ e inferior $\left(L_{i}\right)$, coeficientes de variação amostral $(C V, \%)$, assimetria $\left(A_{P}\right)$ e curtose $(K)$, quantil inferior $\left(Q_{1}\right)$ e superior $\left(Q_{3}\right)$ por fim a amplitude interquartílica $(A I Q)$. Todos os parâmetros estatísticos citados anteriormente foram calculados com o auxilio do software ambiente $R$ versão 3.4.3 ( $R$ DEVELOPMENT CORE TEAM, 2017). Tal análise estatística busca identificar erros grosseiros contidos nos dados da série temporal. A análise exploratória também foi aplicada a série temporal via técnica boxplot nas escalas mensal e anual, com destaque para identificação de valores discrepantes (outliers).

\subsection{TÉCNICA DOS QUANTIS APLICADA AOS DADOS CLIMÁTICOS}

Após as análises estatística e exploratória foi aplicada a técnica dos quantis. A técnica usada neste estudo é baseada na proposta de Xavier e Xavier (1987), por meio dela é possível avaliar a ocorrência de períodos secos ou chuvosos de um total pluviométrico em relação a um conjunto de dados. Os intervalores percentuais de cada quantil, delimitados nos percentis representam as frequências de ocorrência dos eventos pluviométricos extremos de chuva. Santos et al. (2011) afirmam que a vantagem do uso dos quantis é permitir a representação objetiva de um determinado evento climático em termos da sua intensidade ou categoria de ocorrência.

O termo $x$ é a chuva total anual da estação meteorológica, ao longo de anos ininterruptos, sendo uma variável aleatória contínua. O quantil $\left(Q_{p}\right)$, para cada número $\mathrm{p}$ entre 0 e 1 , é o valor de precipitação satisfatório à condição probabilidade $\left(x \leq Q_{p}=p\right)$. Para cada valor observado $x_{0}$ da chuva, o número $\left(0<p_{0}<1\right)$ tal que $f\left(x_{0}\right)$, diz-se de ordem quântica $p_{0}$, associada a $x_{0}$.

Uma interpretação simples para o quantil $Q_{p}$ é baseada em que $\mathrm{p}$ se expressa em potências, isto é, espera-se que em $p \%$ dos anos a altura da chuva $x$ não deve ultrapassar o valor do quantil $Q_{p}$, enquanto para $(100-p) \%$ dos anos esse valor será excedido. Com respeito as ordem quânticas $p=$ 0,25; 0,50; 0.75 são designados como $Q_{0.25} ; Q_{0.50}$ e $Q_{0.75}$ e, ainda são denominados de quartil inferior e superior à mediana.

Os intervalos de cada percentil representam as probabilidades ou frequências esperadas para cada um dos eventos que podem ocorrer na sequência da série temporal de uma variável $x$ (ANANIAS et al., 2010). Portanto, a metodologia adotada consiste na distribuição em ordenamento crescente de uma série amostral contínua. A série temporal usada neste estudo está constituída pelos totais registrados de chuva (anuais e mensais), sendo atribuída uma probabilidade $\mathrm{p}$ univocamente a cada valor amostral. Assim, a série temporal pode ser distribuída sob a forma $\left\{x_{1}, x_{2}, x_{3}, x_{4} \ldots x_{n}\right\}$, na qual $x_{1}$ representa o menor valor e $x_{n}$ o maior valor da série (XAVIER; XAVIER, 1999; SANTOS et al., 2016). E as respectivas ordens quantílicas são 25\%, 50\%, 75\%, $95 \%, 99 \%$ e $100 \%$ para o presente estudo conforme adotado por Souza et al. (2012).

\subsection{BALANÇO HÍDRICO CLIMATOLÓGICO}

O BHC de Resende foi calculado via planilha do Excel desenvolvida por Rolim et al. (1999). O BHC foi determinado com base nos dados médios mensais 
de chuva e temperatura do ar para a série de 1995 a 2017. A capacidade de água disponível (CAD) foi definida o valor de $100 \mathrm{~mm}$. O método de Thorthwaite e Mather (1955) foi usado no cálculo do BHC e maiores informações encontramse em Rolim et al. (1998) e Rolim et al. (1999). Posteriormente, foram calculados os BHCs para os anos mais secos (1999 e 2017) e mais chuvosos (2008 e 2009) da série histórica para avaliar a variação das características hídricas em anos sob condições extremas de chuva.

\section{RESULTADOS E DISCUSSÃO}

\subsection{FALHAS DE DADOS E ESTATÍSTICAS DESCRITIVAS EXPLORATÓRIAS APLICADAS À SÉRIE TEMPORAL CLIMÁTICA}

A análise de falha nos dados da série temporal de chuva em Resende mostrou que os meses com maiores percentuais de falhas nos meses de abril $(4,35 \%)$ e maio $(4,35 \%)$ em comparação aos demais meses do ano, que não presentou registros de falhas. Em relação à temperatura do ar, também foram registados percentuais de falhas iguais nos meses de janeiro, fevereiro e junho com percentuais de 4,35\%, respectivamente (Tabelas 1 e 2 ).

Os resultados obtidos mostram que período seco em Resende ocorre entre os meses de maio a agosto. Os menores totais de chuva foram superiores à mediana, registradas no intervalo entre 23,1 e $45,5 \mathrm{~mm}$, enquanto que a temperatura do ar foi abaixo da mediana, no intervalo entre 18,3 e $20,3^{\circ} \mathrm{C}$, ambas entre o $1^{\circ}$ e o $3^{\circ}$ quartil, respectivamente (Figuras 3 e 4). Destaque para a maior assimetria positiva observada na estação seca (abril a setembro) e úmida (outubro a março). O mês de janeiro sobressaiu em relação aos demais meses do ano, com assimetria negativa quanto à chuva, isso se deve a elevada altitude da região, e índices pluviométricos altos, que compreendem o período de transição entre as estações da primavera e do verão, ressaltando-se a importância dos sistemas meteorológicos na geração de chuvas no estado do Rio de Janeiro, como a ZCAS, a convecção local, os Complexos Convectivos de Mesoescala (CCM's) e os SF, principais mecanismos formadores de chuva (KODAMA, 1993; CARVALHO, 2002; ZANDONADI et al., 2015).

$\mathrm{Na}$ estação seca, ocorreu forte assimetria negativa nos meses de maio a agosto para temperatura do ar. Na estação úmida, houve alta variabilidade da chuva quanto ao parâmetro assimetria, ora negativo ora positivo, nos meses de setembro a abril, isso se deve aos diferentes fatores fisiográficos e dinâmicos que atuam na região de Resende. Nesta região a estação de transição é nitidamente observada neste período, onde os meses com os menores registros de chuva foram maio, junho, julho e agosto (Figura 3).

Ressalta-se a presença de outliers durante a estação seca para ambas as variáveis climáticas no período de estudo. A região do Médio Paraíba é fortemente influenciada pelas circulações das brisas vale/montanha, convecção local, CCM, SF, ZCAS, Alta Subtropical do Atlântico Sul - ASAS e Alta da Bolívia BA (CARVALHO, 2002; ANDRÉ et al., 2008; BRITO et al., 2016; SOBRAL et al., 2018), tal variabilidade de sistemas meteorológicos em multiescala contribuem para o surgimento de outliers nas séries temporais de chuva e temperatura do ar. 


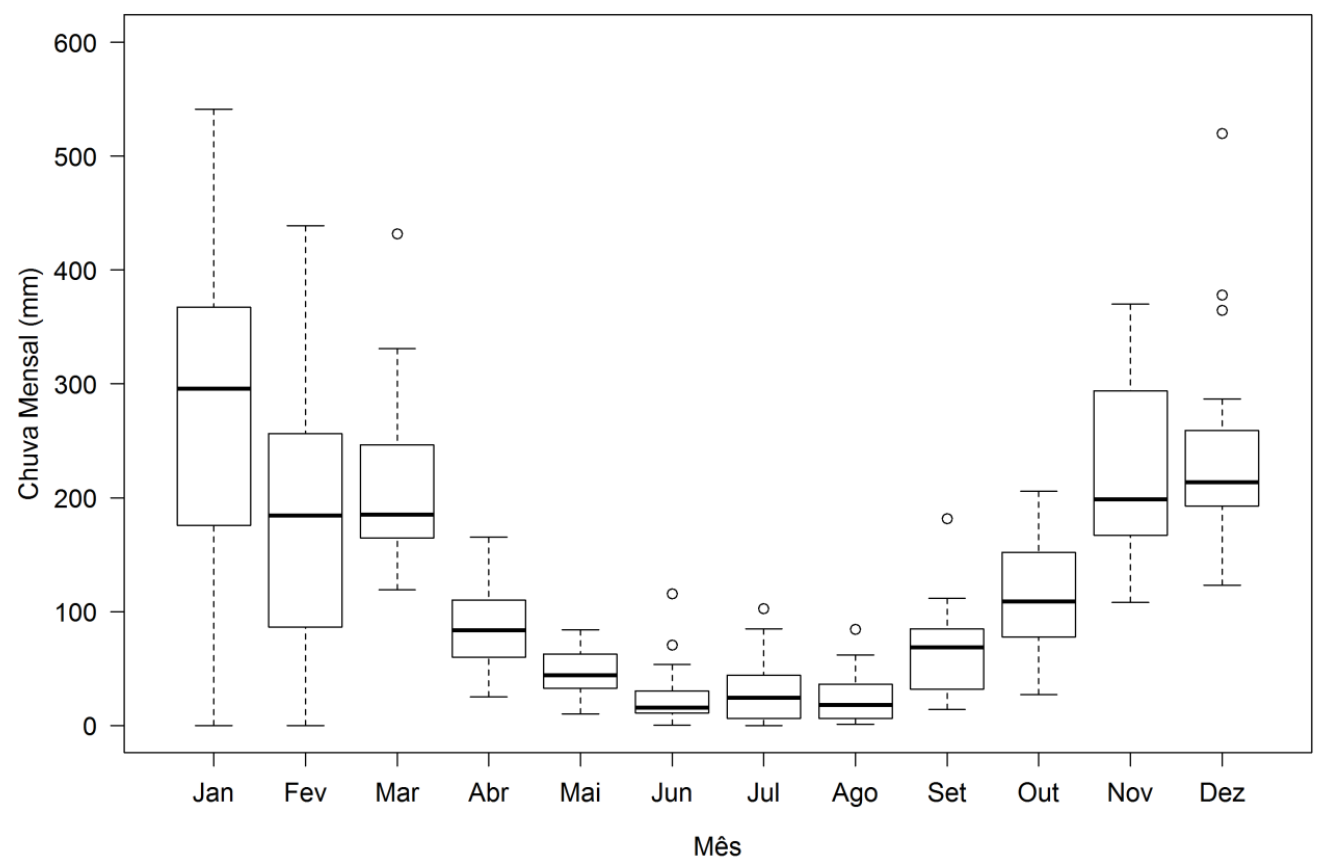

Figura 3 - Boxplot da chuva mensal (mm) em Resende (RJ) no período de 1995 a 2017.

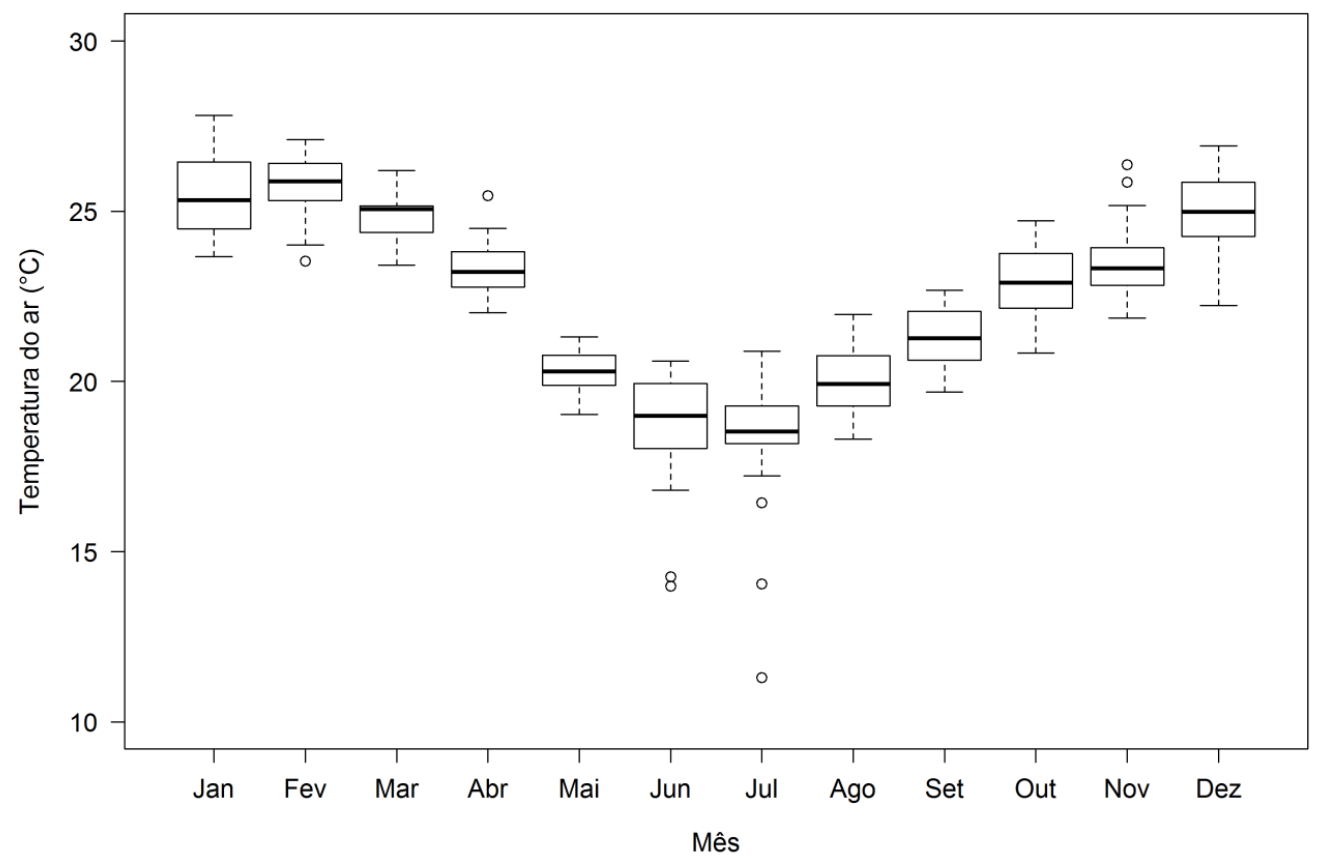

Figura 4 - Boxplot da temperatura média mensal do ar $\left({ }^{\circ} \mathrm{C}\right)$ em Resende (RJ) para o período de 1995 a 2017.

Quanto à forma das distribuições da chuva e temperatura do ar mensal se aproximam de forma simétrica. A média e a mediana dos dados das séries temporais foram iguais, sendo comprovado pelos menores valores dos coeficientes Ap para a chuva $(0,08$ a 1,09) e Ap para a temperatura do ar $(-0,03$ a -1,91), conforme apresentam as tabelas 1 e 2 , sendo que resultados similares 
foram obtidos por Machiwal et al. (2015) para região de Gujarat, Índia. O CV amostral aplicado à chuva mostrou que todos os meses da série temporal apresentaram valores superiores a $30 \%$, demonstrando uma alta variabilidade temporal das chuvas, sendo os meses de junho $(104,5 \%)$, julho $(94,8 \%)$ e agosto $(94,5 \%)$ com os maiores valores deste parâmetro (CV) e correspondentes ao do inverno (Tabela 1).

TABELA 1 - Parâmetros estatísticos da chuva: média $(\bar{x})$, mediana $\left(M_{d}\right)$, desvio padrão $\left(D_{P}\right)$, valor máximo $\left(V M_{a}\right)$ e mínimo $\left(V M_{i}\right)$, amplitude total $\left(A_{t}\right)$, limites superior $\left(L_{s}\right)$ e inferior $\left(L_{i}\right)$, coeficientes de variação $(C V)$, assimetria $\left(A_{p}\right)$ e curtose $(K)$, quantil inferior $\left(Q_{1}\right)$ e superior $\left(Q_{3}\right)$, amplitude interquartílica $(A I Q)$ e percentual $(\%)$ de falhas dos dados em Resende (RJ).

\begin{tabular}{|c|c|c|c|c|c|c|c|c|}
\hline \multirow[b]{2}{*}{ Meses } & \multirow{2}{*}{$\begin{array}{c}\text { Falhas } \\
(\%)\end{array}$} & \multirow{2}{*}{$\begin{array}{c}\bar{x} \\
(\mathrm{~mm})\end{array}$} & \multirow{2}{*}{$\begin{array}{c}M_{d} \\
(\mathrm{~mm})\end{array}$} & \multicolumn{3}{|c|}{ Valor } & \multicolumn{2}{|c|}{ Limite } \\
\hline & & & & $\begin{array}{l}V M_{i} \\
(\mathrm{~mm})\end{array}$ & $\begin{array}{l}V M_{a} \\
(\mathrm{~mm})\end{array}$ & $\begin{array}{c}A_{t} \\
(\mathrm{~mm})\end{array}$ & $\begin{array}{c}L_{i} \\
(\mathrm{~mm})\end{array}$ & $\begin{array}{c}L_{S} \\
(\mathrm{~mm})\end{array}$ \\
\hline JAN & 0,00 & 277,99 & 295,90 & 0,00 & 541,10 & 541,10 & $-111,20$ & 654,40 \\
\hline FEV & 0,00 & 190,91 & 184,30 & 0,00 & 438,80 & 438,80 & $-168,38$ & 511,43 \\
\hline MAR & 0,00 & 208,27 & 185,30 & 119,40 & 431,60 & 312,20 & 41,90 & 369,10 \\
\hline$A B R$ & 4,35 & 85,22 & 83,70 & 25,00 & 165,60 & 140,60 & $-15,03$ & 185,18 \\
\hline MAI & 4,35 & 45,46 & 44,00 & 10,10 & 84,10 & 74,00 & $-12,53$ & 107,68 \\
\hline JUN & 0,00 & 24,93 & 15,60 & 0,20 & 115,60 & 115,40 & $-17,73$ & 58,88 \\
\hline JUL & 0,00 & 28,77 & 24,30 & 0,00 & 102,60 & 102,60 & $-50,73$ & 101,08 \\
\hline AGO & 0,00 & 23,12 & 17,90 & 1,10 & 84,50 & 83,40 & $-38,90$ & 81,10 \\
\hline SET & 0,00 & 64,27 & 68,60 & 14,10 & 181,50 & 167,40 & $-47,75$ & 164,65 \\
\hline OUT & 0,00 & 117,32 & 109,00 & 27,20 & 205,60 & 178,40 & $-34,18$ & 264,03 \\
\hline NOV & 0,00 & 224,84 & 198,80 & 108,20 & 370,00 & 261,80 & $-22,93$ & 484,08 \\
\hline \multirow[t]{2}{*}{ DEZ } & 0,00 & 237,04 & 213,60 & 123,20 & 520,00 & 396,80 & 93,20 & 358,94 \\
\hline & \multicolumn{4}{|c|}{ Coeficientes } & & \multicolumn{2}{|c|}{ Quartil } & IO \\
\hline Meses & \multicolumn{2}{|c|}{$\begin{array}{l}C V \\
(\%)\end{array}$} & $A_{p}$ & $\boldsymbol{K}$ & $\begin{array}{c}P \\
(\mathrm{~mm})\end{array}$ & $\begin{array}{c}Q_{1} \\
(\mathrm{~mm})\end{array}$ & $\begin{array}{c}Q_{3} \\
(\mathrm{~mm})\end{array}$ & $(\mathrm{mm})$ \\
\hline JAN & \multicolumn{2}{|c|}{48,52} & $-0,26$ & $-0,67$ & 134,88 & 175,90 & 367,30 & 191,40 \\
\hline FEV & \multicolumn{2}{|c|}{59,18} & 0,35 & $-0,80$ & 112,97 & 86,55 & 256,50 & 169,95 \\
\hline MAR & \multicolumn{2}{|c|}{35,76} & 1,14 & 1,28 & 74,48 & 164,60 & 246,40 & 81,80 \\
\hline$A B R$ & \multicolumn{2}{|c|}{42,27} & 0,31 & $-0,76$ & 36,02 & 60,05 & 110,10 & 50,05 \\
\hline MAI & \multicolumn{2}{|c|}{49,62} & 0,08 & $-1,14$ & 22,56 & 32,55 & 62,60 & 30,05 \\
\hline JUN & \multicolumn{2}{|c|}{104,52} & 1,98 & 3,97 & 26,06 & 11,00 & 30,15 & 19,15 \\
\hline JUL & \multicolumn{2}{|c|}{94,83} & 1,02 & 0,48 & 27,29 & 6,20 & 44,15 & 37,95 \\
\hline AGO & \multicolumn{2}{|c|}{94,58} & 1,09 & 0,51 & 21,86 & 6,10 & 36,10 & 30,00 \\
\hline SET & \multicolumn{2}{|c|}{60,07} & 0,97 & 1,30 & 38,61 & 31,90 & 85,00 & 53,10 \\
\hline OUT & \multicolumn{2}{|c|}{42,39} & 0,14 & $-1,17$ & 49,74 & 77,65 & 152,20 & 74,55 \\
\hline NOV & \multicolumn{2}{|c|}{35,51} & 0,26 & $-1,30$ & 79,84 & 167,20 & 293,95 & 126,75 \\
\hline DEZ & \multicolumn{2}{|c|}{36,86} & 1,55 & 2,55 & 87,38 & 192,85 & 259,28 & 66,43 \\
\hline
\end{tabular}

Para a temperatura do ar foram registados baixos valores do $\mathrm{CV}$ entre $2,84 \%$ a $11,26 \%$ em todo o período de estudo. Os maiores valores de $D_{P}$ e $A I Q$ para a chuva demonstraram alta variabilidade dos dados em torno da média, principalmente nos meses da estação seca (maio, junho e julho). Comparativamente, a temperatura do ar apresentou as menores variações, 
quanto ao $D_{P}(0,63$ a 2,06) e $A I Q(0,78$ a 1,96). Entretanto, observou-se que os meses de junho e julho se sobressaíram em relação aos demais, por apresentarem a média e mediana similares a estação seca. A forma da distribuição da temperatura do ar é praticamente simétrica, e altamente influenciada pelos baixos valores do $C V, D_{P}$ e $A I Q$ da temperatura do ar (Tabela 2).

Os coeficientes de curtose $(K)$ revelaram para a chuva e temperatura do ar um grau de achatamento da curva de frequência do tipo leptocúrtica $(K>3)$, nos meses de junho e julho. Para os demais meses, o coeficiente $K$ mostrou um grau de achatamento platicúrtica $(K<3)$. Os resultados foram próximos aos encontrados por Lo Presti et al. (2010) na bacia do Rio Candelaro, região da Itália, sendo observados valores do coeficiente de assimetria entre 2,66 a 5,81 e curtose 10,13 a 21,78, respectivamente.

Tabela 2. Parâmetros estatísticos da temperatura do ar: média $(\bar{x})$, mediana $\left(M_{d}\right)$, desvio padrão $\left(D_{P}\right)$, valor máximo $\left(V M_{a}\right)$ e mínimo $\left(V M_{i}\right)$, amplitude total $\left(A_{t}\right)$, limites superior $\left(L_{s}\right)$ e inferior $\left(L_{i}\right)$, coeficientes de variação $(C V)$, assimetria $\left(A_{p}\right)$ e curtose $(K)$, quantil inferior $\left(Q_{1}\right)$ e superior $\left(Q_{3}\right)$, amplitude interquartílica $(A I Q)$ e percentual (\%) de falhas dos dados em Resende (RJ).

\begin{tabular}{|c|c|c|c|c|c|c|c|c|}
\hline \multirow[b]{2}{*}{ Meses } & \multirow{2}{*}{$\begin{array}{c}\text { Falhas } \\
\text { (\%) }\end{array}$} & \multirow{2}{*}{$\begin{array}{c}\bar{x} \\
\left(^{\circ} \mathrm{C}\right)\end{array}$} & \multirow{2}{*}{$\begin{array}{l}M_{d} \\
\left({ }^{\circ} \mathrm{C}\right)\end{array}$} & \multicolumn{3}{|c|}{ Valor } & \multicolumn{2}{|c|}{ Limite } \\
\hline & & & & $\begin{array}{l}V M_{i} \\
\left({ }^{\circ} \mathrm{C}\right)\end{array}$ & $\begin{array}{l}V M_{a} \\
\left({ }^{\circ} \mathrm{C}\right)\end{array}$ & $\begin{array}{c}A_{t} \\
\left({ }^{\circ} \mathrm{C}\right)\end{array}$ & $\begin{array}{c}L_{i} \\
\left({ }^{\circ} \mathrm{C}\right)\end{array}$ & $\begin{array}{c}L_{s} \\
\left({ }^{\circ} \mathrm{C}\right)\end{array}$ \\
\hline JAN & 4,35 & 25,47 & 25,33 & 23,67 & 27,82 & 4,15 & 21,55 & 29,39 \\
\hline FEV & 4,35 & 25,76 & 25,88 & 23,54 & 27,11 & 3,57 & 23,69 & 28,04 \\
\hline MAR & 0,00 & 24,83 & 25,06 & 23,41 & 26,19 & 2,78 & 23,21 & 26,32 \\
\hline$A B R$ & 0,00 & 23,32 & 23,22 & 22,03 & 25,46 & 3,43 & 21,19 & 25,39 \\
\hline MAI & 0,00 & 20,27 & 20,30 & 19,04 & 21,30 & 2,27 & 18,55 & 22,10 \\
\hline JUN & 4,35 & 18,60 & 18,99 & 13,98 & 20,61 & 6,62 & 15,19 & 22,79 \\
\hline JUL & 0,00 & 18,28 & 18,53 & 11,31 & 20,89 & 9,58 & 16,52 & 20,95 \\
\hline AGO & 0,00 & 19,93 & 19,93 & 18,31 & 21,97 & 3,66 & 17,09 & 22,95 \\
\hline SET & 0,00 & 21,37 & 21,27 & 19,69 & 22,69 & 3,00 & 18,46 & 24,22 \\
\hline OUT & 0,00 & 22,91 & 22,90 & 20,83 & 24,73 & 3,89 & 19,75 & 26,16 \\
\hline NOV & 0,00 & 23,55 & 23,33 & 21,87 & 26,36 & 4,50 & 21,16 & 25,59 \\
\hline DEZ & 0,00 & 24,96 & 24,99 & 22,24 & 26,92 & 4,68 & 21,87 & 28,25 \\
\hline \multirow[b]{2}{*}{ Meses } & \multicolumn{4}{|c|}{ Coeficientes } & & \multicolumn{2}{|c|}{ Quartil } & \\
\hline & \multicolumn{2}{|c|}{$\begin{array}{l}C V \\
\text { (\%) }\end{array}$} & $A_{p}$ & K & $\begin{array}{c}D_{P} \\
\left({ }^{\circ} \mathrm{C}\right)\end{array}$ & $\begin{array}{c}Q_{1} \\
\left({ }^{\circ} \mathrm{C}\right)\end{array}$ & $\begin{array}{c}Q_{3} \\
\left({ }^{\circ} \mathrm{C}\right)\end{array}$ & $\begin{array}{l}A I Q \\
\left({ }^{\circ} \mathrm{C}\right)\end{array}$ \\
\hline JAN & \multicolumn{2}{|c|}{4,98} & 0,31 & $-1,22$ & 1,27 & 24,49 & 26,45 & 1,96 \\
\hline FEV & \multicolumn{2}{|c|}{3,49} & $-0,80$ & $-0,04$ & 0,90 & 25,32 & 26,41 & 1,09 \\
\hline MAR & \multicolumn{2}{|c|}{2,84} & $-0,22$ & $-0,66$ & 0,71 & 24,38 & 25,15 & 0,78 \\
\hline$A B R$ & \multicolumn{2}{|c|}{3,58} & 0,56 & $-0,19$ & 0,83 & 22,77 & 23,82 & 1,05 \\
\hline MAI & \multicolumn{2}{|c|}{3,10} & $-0,30$ & $-0,96$ & 0,63 & 19,88 & 20,77 & 0,89 \\
\hline JUN & \multicolumn{2}{|c|}{9,30} & $-1,32$ & 1,20 & 1,73 & 18,04 & 19,94 & 1,90 \\
\hline JUL & \multicolumn{2}{|c|}{11,26} & $-1,91$ & 3,72 & 2,06 & 18,18 & 19,29 & 1,11 \\
\hline AGO & \multicolumn{2}{|c|}{5,19} & $-0,03$ & $-1,09$ & 1,03 & 19,29 & 20,75 & 1,46 \\
\hline SET & \multicolumn{2}{|c|}{4,14} & $-0,24$ & $-1,26$ & 0,88 & 20,62 & 22,06 & 1,44 \\
\hline OUT & \multicolumn{2}{|c|}{5,18} & $-0,18$ & $-1,09$ & 1,19 & 22,16 & 23,76 & 1,60 \\
\hline NOV & \multicolumn{2}{|c|}{4,89} & 0,77 & 0,00 & 1,15 & 22,82 & 23,93 & 1,11 \\
\hline DEZ & \multicolumn{2}{|c|}{4,70} & $-0,25$ & $-0,52$ & 1,17 & 24,26 & 25,86 & 1,60 \\
\hline
\end{tabular}




\subsection{VARIABILIDADE ANUAL E MENSAL DA CHUVA E DA TEMPERATURA DO AR}

Os maiores valores de chuva acumulada anual foram nos anos de 1996, 2000, 2004, 2005, 2006, 2008, 2009, 2010, 2011, 2013 e 2016. Os anos 1996, 2004, 2005, 2006, 2009, 2010 e 2011 são categorizados como anos de ocorrência de El Niño Fraco, seguido dos anos de 2008, 2013 e 2016 de El Niño Moderado e, por fim, apenas o ano de 2000 correspondentes a La Niña Fraca. Os resultados foram similares aos obtidos por Costa et al. (2012) nos municípios de Volta Redonda, Barra Mansa, Itatiaia, Piraí, Barra do Piraí e Rio Claro, com valores médios anuais superiores a $1300 \mathrm{~mm}$. Segundo Sobral et al. (2018), nos municípios citados anteriormente é comum à ocorrência de chuvas orográficas. Elas se formam nas Serras do Mar (litoral) e da Mantiqueira (interior). Os menores registros ocorreram nos demais anos da série temporal (Figura 5a). As diferenças nos totais anuais de chuva se devem a influência da orografia. As menores diferenças anuais pluviométricas acumuladas foram registradas abaixo da média nos percentis dos quantis de 25\% (1240,33 mm) e 50\% (1422,00 $\mathrm{mm}$ ) da média e mediana. Enquanto, as maiores diferenças superior à média foram observados nos percentis de 75\% (1764,93 mm) a 100\% (2110,20 mm) dos quantis da mediana (Figura 5b).

Na escala anual, verifica-se similaridade na temperatura do ar quanto a sua variabilidade ao longo dos anos. Os valores da temperatura anual foram abaixo da média $\left(22,4^{\circ} \mathrm{C}\right)$ correspondem aos anos de 1995, 1999, 2000, 2003, 2004, 2008, 2016 e 2017 (Figura 6a). Houve significativa variação da temperatura anual para os percentis dos quantis de $25 \%\left(21,94^{\circ} \mathrm{C}\right)$ e $50 \%$ $\left(22,51^{\circ} \mathrm{C}\right.$ ) da mediana (Figura 6b), embora não tenham sido observadas variações significativas na temperatura anual para os percentis acima da média e mediana dos quantis de $75 \%\left(22,94^{\circ} \mathrm{C}\right), 95 \%\left(23,34^{\circ} \mathrm{C}\right), 99 \%\left(23,37^{\circ} \mathrm{C}\right)$ e $100 \%\left(23,38^{\circ} \mathrm{C}\right)$ (Figura $\left.5 \mathrm{~b}\right)$.
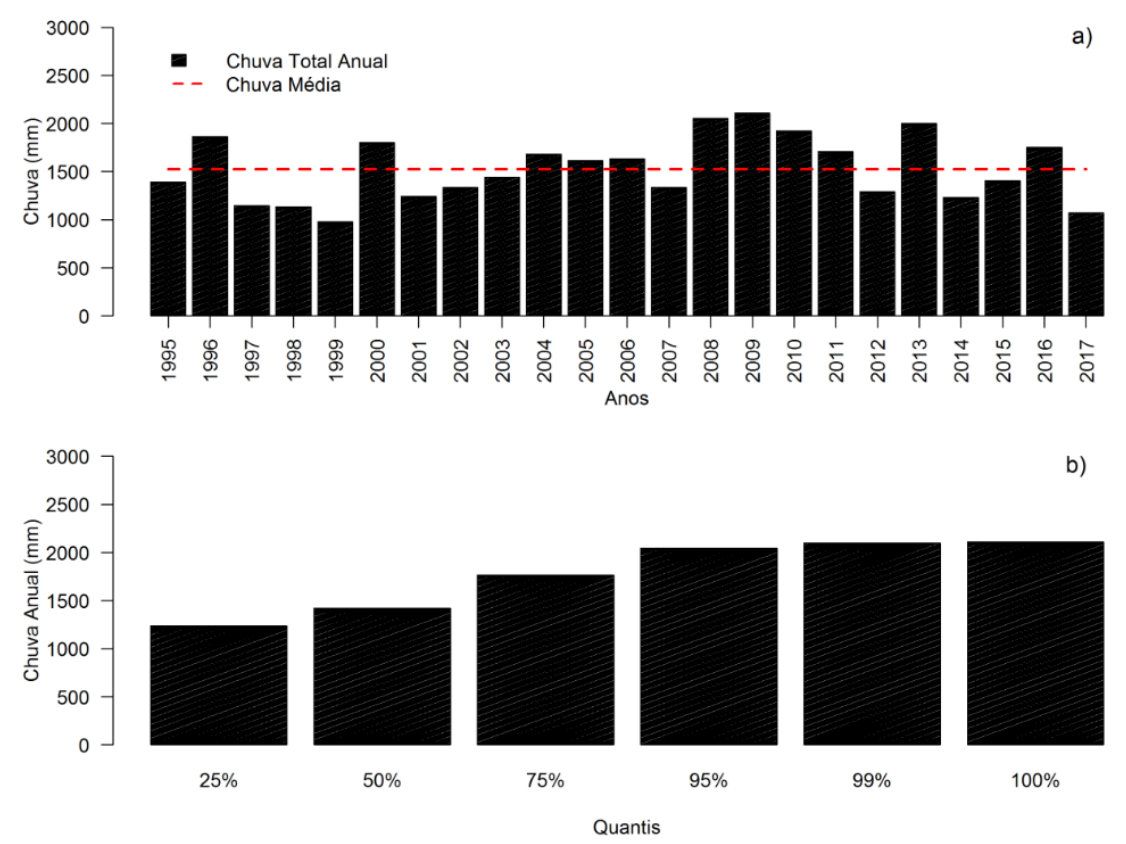

Figura 5 - Chuva acumulada média anual $(\mathrm{mm})$ em Resende (a) e valores dos quantis (\%) de chuva anual (b) para o período de 1995 a 2017. 

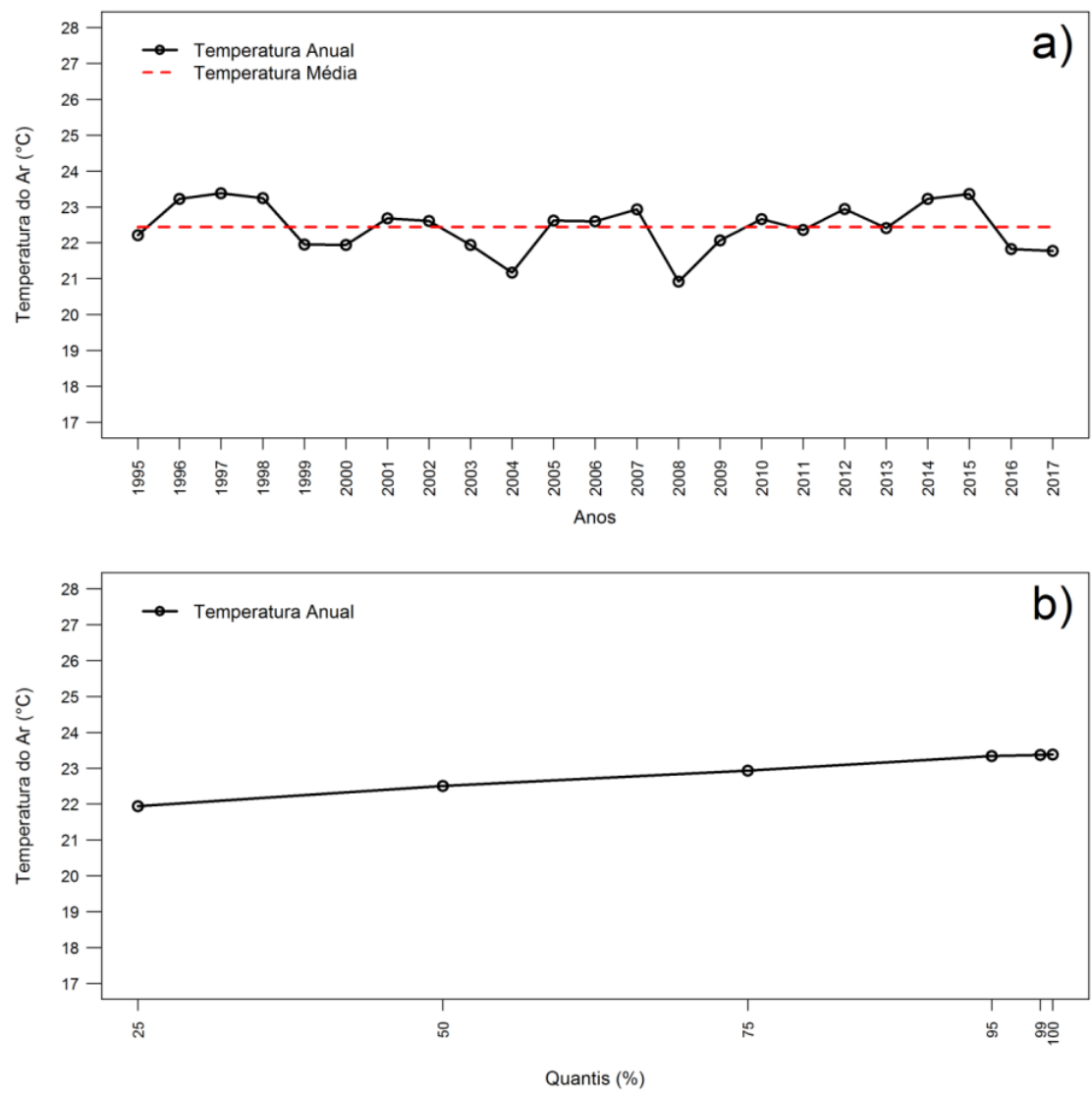

Figura 6 - Temperatura anual e média $\left({ }^{\circ} \mathrm{C}\right)$ da estação meteorológica automática de Resende (a) e valores dos quantis (\%) de temperatura anual (b) para o período de 1995 a 2017.

A análise da variabilidade da chuva média mensal no período de estudo revelou a ocorrência de períodos secos nos meses de junho $(9,13 \mathrm{~mm})$, julho $(4,48 \mathrm{~mm})$ e agosto $(5,45 \mathrm{~mm})$. Na estação de inverno, para os percentis dos quantis a $25 \%$ da média não ultrapassou a chuva média mensal de 25,61 mm (Figura 7). Com o percentil do quantil de $50 \%$, a chuva foi abaixo da média mensal nos meses de junho $(15,55 \mathrm{~mm})$, julho $(24,15 \mathrm{~mm})$ e agosto $(16,70$ $\mathrm{mm}$ ). Na transição entre as estações seca e chuvosa ocorre nos meses de setembro e outubro, com valores de chuva abaixo da média mensal $(127,35$ $\mathrm{mm}$ ), para os percentis dos quantis de $25 \%, 50 \%, 75 \%$ e $95 \%$, que corresponde em setembro a 28,55 e 109,42 mm e outubro entre 72,13 e 107,40 $\mathrm{mm}$. Porém, valores de chuva acima da média mensal foram registrados para os percentis dos quantis de $75 \%, 95 \%, 99 \%$ e $100 \%$.

A estação das chuvas, conforme os resultados observados na Figura 7(a) ocorrem nos meses de novembro a março, em que nota-se um acentuado aumento da chuva no decorrer do tempo, para os percentis dos quantis de 50 a $100 \%$, onde de acordo com Figura 7 (c) e (b), os meses de novembro $(164,85$ $\mathrm{mm}$ e 197,30 mm), dezembro $(187,33 \mathrm{~mm})$, janeiro $(162,68 \mathrm{~mm})$, fevereiro $(84,28 \mathrm{~mm}$ e $178,45 \mathrm{~mm})$ e março $(157,83 \mathrm{~mm}$ e $185,00 \mathrm{~mm})$, seguida de chuvas abaixo da média mensal $(209,39 \mathrm{~mm})$ para os percentis dos quantis de $25 \%$ e $50 \%$, com exceção dos meses de dezembro (212,90 mm) e janeiro $(284,35 \mathrm{~mm})$ para o percentil do quantil de $50 \%$ com valores de chuva mensal 
acima da média de 209,39 mm. Porém, para os demais percentis dos quantis de $75 \%, 95 \%, 99 \%$ e $100 \%$ observou-se um significativo aumento da chuva na estação das chuvas na região.

Desta forma esses resultados corroboram com Silva e Dereczynski (2014), em que a chuva sofre considerável influência da topografia, com máximos nas áreas de elevada altitude e mínimos sobre as regiões das Baixadas Litorâneas e Costa. A passagem de SF, estabelecimento de ZCAS, ocorrência de SCM e a circulação da brisa marítima interagem com a orografia local, com isso produz irregularidades espaciais no campo de chuva. No ERJ, os maiores índices pluviométricos médios anuais encontram-se na divisa da região Metropolitana e das Baixadas Litorâneas com a região Serrana, onde a chuva varia entre 2500 e $2800 \mathrm{~mm}$ (SOBRAL et al., 2018). No inverno, existe uma redução brusca dos totais de chuva, sendo a chuva nesta estação oriunda da maior entrada de SF. Na região Serrana e em suas proximidades, o total pluviométrico na estação do verão (inverno) fica em média de 600 a $1350 \mathrm{~mm}$ (até $300 \mathrm{~mm}$ ). Durante as estações de transição, a primavera possui totais pluviométricos superiores ao outono. Na primavera possui o maior número de SF pela região Sudeste do Brasil, principalmente no ERJ (OLIVEIRA JÚNIOR et al., 2014).

Para a temperatura os percentis dos quantis de $25 \%$ a $100 \%$ na estação seca variaram entre $17,98^{\circ} \mathrm{C}$ a $20,60^{\circ} \mathrm{C}$ (junho), $18,05^{\circ} \mathrm{C}$ a $20,89^{\circ} \mathrm{C}$ (julho) e de $19,03^{\circ} \mathrm{C}$ a $21,97^{\circ} \mathrm{C}$ (agosto), com exceção de agosto, ainda apresentou valores dos percentis dos quantis de $95 \%$, $99 \%$ e $100 \%\left(22^{\circ} \mathrm{C}\right)$ similares. Seguidos das temperaturas abaixo da média na estação de transição (Figura 8), que apresentaram menores valores dos percentis dos quantis a $25 \%, 50 \%$ e $75 \%$ abaixo da média mensal de $22,14^{\circ} \mathrm{C}$, e acima da média mensal para os percentis dos quantis de $95 \%, 99 \%$ e $100 \%$ no mês de setembro. Situação contrária foi observada no mês de outubro para os percentis dos quantis a $50 \%$, $75 \%, 95 \%, 99 \%$ e $100 \%$ para valores superiores à média mensal de $22,14^{\circ} \mathrm{C}$, a exceção foi o percentil do quantil a $25 \%$ da média que apresenta idênticos à média mensal na estação de transição.

Resultados semelhantes foram encontrados na estação de transição para os campos médios de temperatura mínima do ar sobre o ERJ, no qual a altitude e o oceano foram os principais fatores controladores desta variável. Foram constatadas pelos autores as menores temperaturas mínimas médias durante todo o ano na região Serrana, em que a temperatura, oscilando entre 9,5 e 11 ${ }^{\circ} \mathrm{C}$ na estação do inverno e entre 15,5 e $17^{\circ} \mathrm{C}$ no verão. Nas regiões do Vale do Paraíba e Centro-Sul, as temperaturas mínimas oscilam entre 12,5 e $14^{\circ} \mathrm{C}$ no inverno e entre 18,5 e $20^{\circ} \mathrm{C}$ no verão.

Quanto à temperatura máxima média no estado do Rio de Janeiro, Silva e Dereczynski (2014) inferiram que na região do Vale do Paraíba as temperaturas máximas médias variam na estação do inverno entre 24,5 e $26^{\circ} \mathrm{C}$ e no verão entre 29 e $30,5^{\circ} \mathrm{C}$. Esses resultados estão de acordo com os encontrados neste trabalho para o município de Resende. 

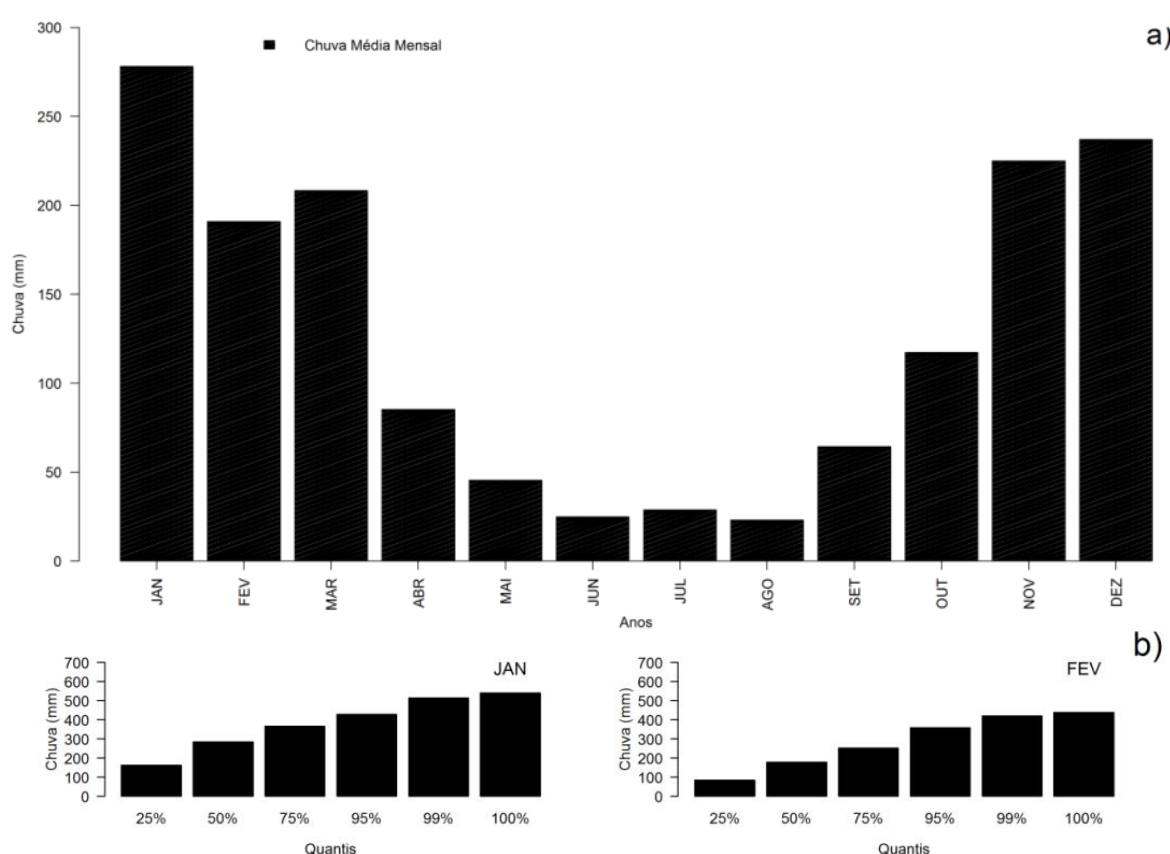

b)
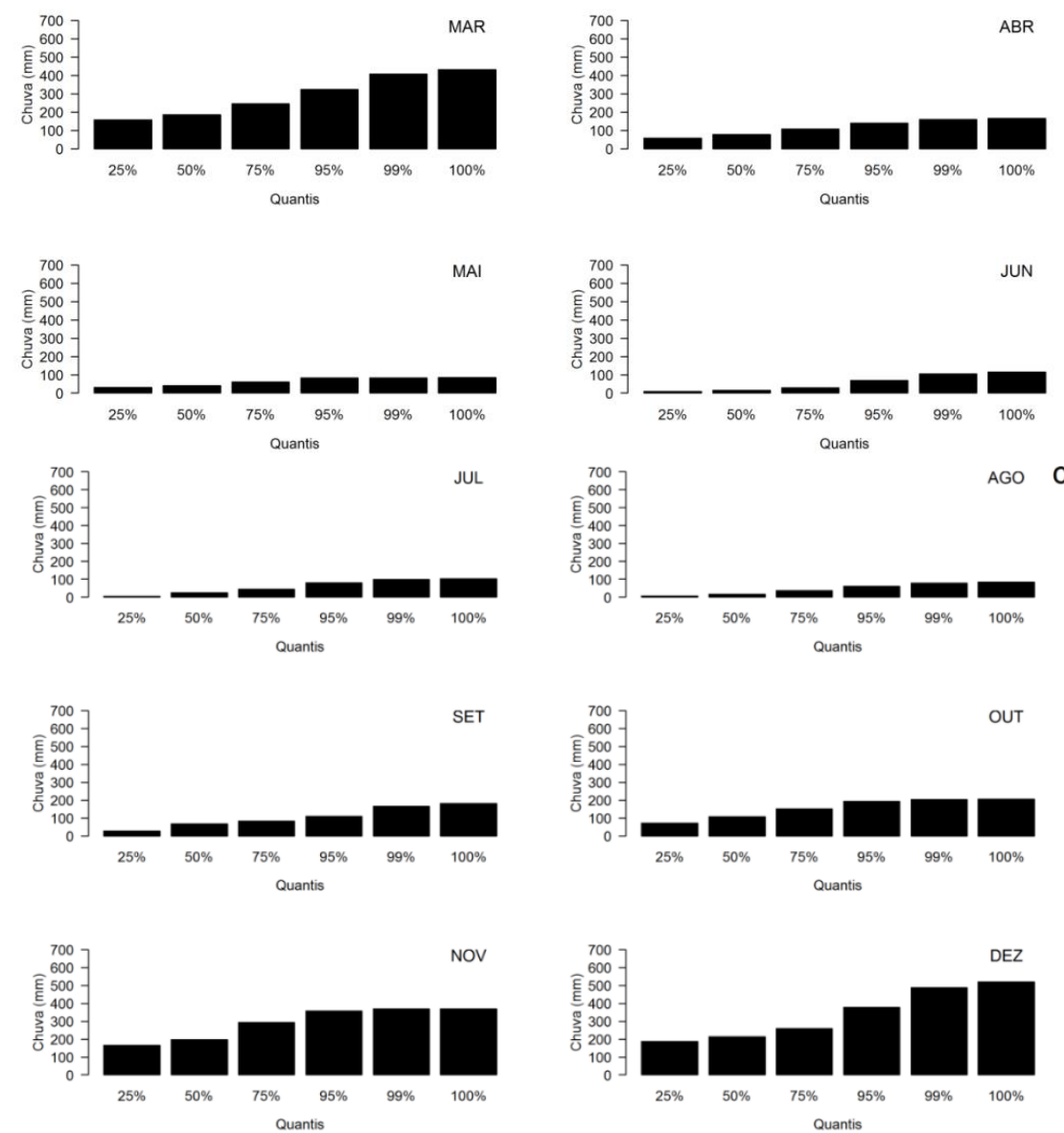

Figura 7 - Chuva média mensal $(\mathrm{mm})$ da estação meteorológica automática de Resende (a) e valores dos quantis (\%) de chuva mensal (b) e (c) para o período de 1995 a 2017. 


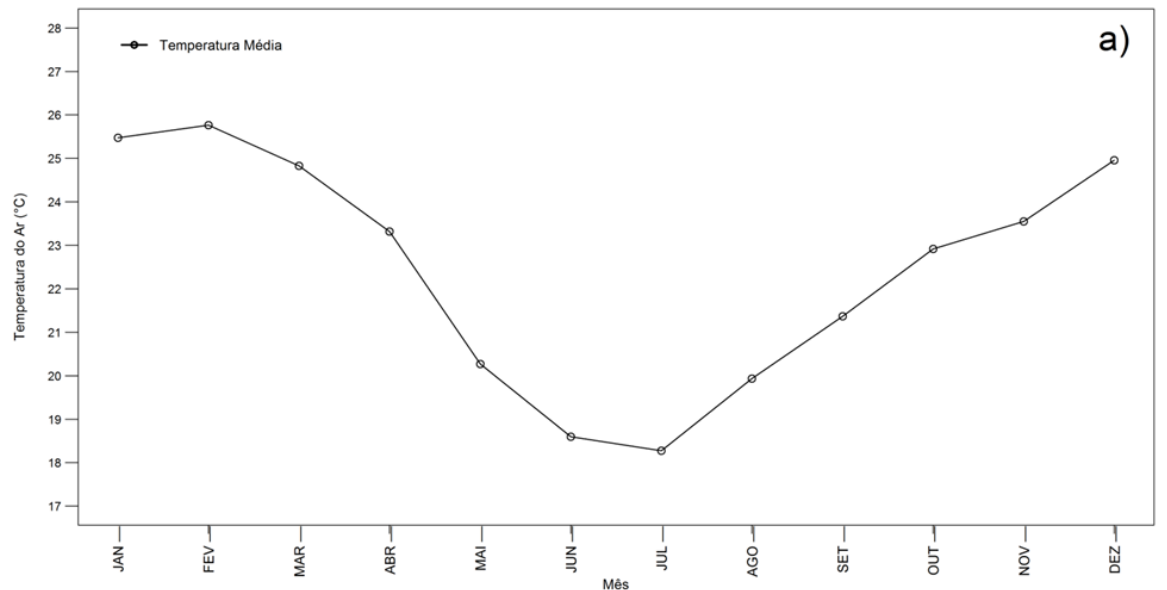

b)
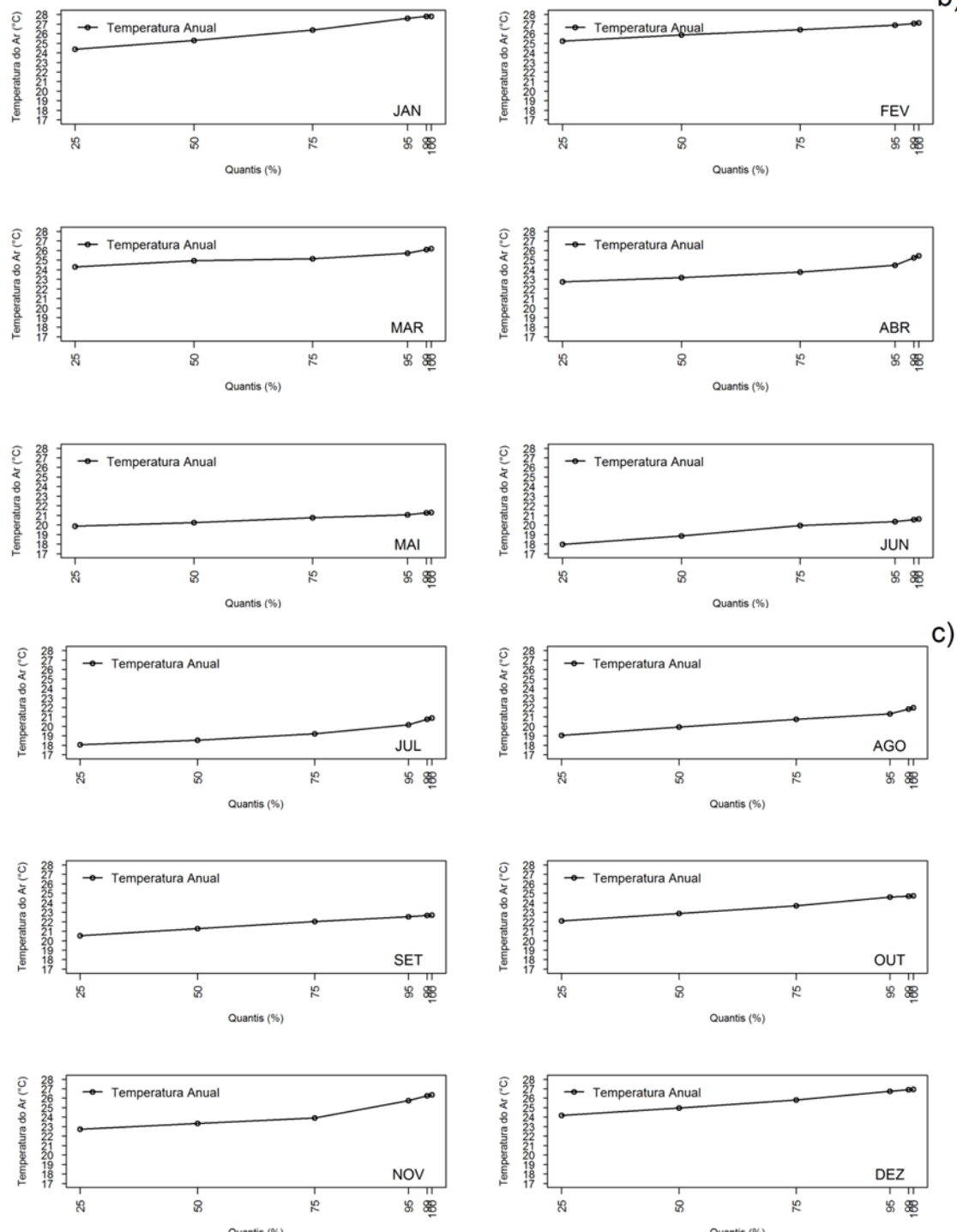

Figura 8 - Temperatura média mensal do ar $\left({ }^{\circ} \mathrm{C}\right)$ da estação meteorológica automática de Resende (a) e valores dos quantis (\%) de temperatura média mensal (b) e (c) para o período de 1995 a 2017. 


\subsection{BALANÇO HÍDRICO CLIMÁTICO DO MUNICÍPIO DE RESENDE}

Os valores de ETP mostrou-se mais elevada entre o período de primavera e verão, entre setembro e março, com valor médio anual de $1126,1 \mathrm{~mm}$. A evapotranspiração real (ETR) segue o mesmo padrão da ETP $(1083,9 \mathrm{~mm})$, com menores valores no período seco, inferiores a $100 \mathrm{~mm}$ entre abril e setembro. A deficiência hídrica (DEF) foi maior no período de estiagem (abril a agosto), prolongando-se até o inicio de setembro $(44,2 \mathrm{~mm})$. O EXC no período de estudo mostrou que todos os meses da estação chuvosa totalizaram 444,3 mm. Esta variação ocorreu entre os meses de outubro a março, com os meses de outubro e novembro caracterizados como um período de reposição de água no solo (Figura 9). Os resultados obtidos coincidem com os resultados de Brandão et al. (2016) em um estudo sobre a determinação do perfil climatológico do município de Santo Antônio de Pádua-RJ.

Os resultados obtidos do BHC mostraram uma distribuição irregular da chuva, com duas estações bem definidas. A estação chuvosa inicia-se em outubro, com o maior excedente hídrico (EXC) em janeiro $(135,6 \mathrm{~mm})$ e em dezembro $(102,9 \mathrm{~mm})$, e termina em março $(84,2 \mathrm{~mm})$. O período entre abril e setembro caracteriza-se pela deficiência hídrica, sendo que o mês mais seco é agosto, no qual a deficiência hídrica é de 19,2 mm. Estas características atestam as características do clima tropical próprio a esta região do território brasileiro (KELLER FILHO et al., 2005) e do ERJ (SOBRAL et al., 2018).
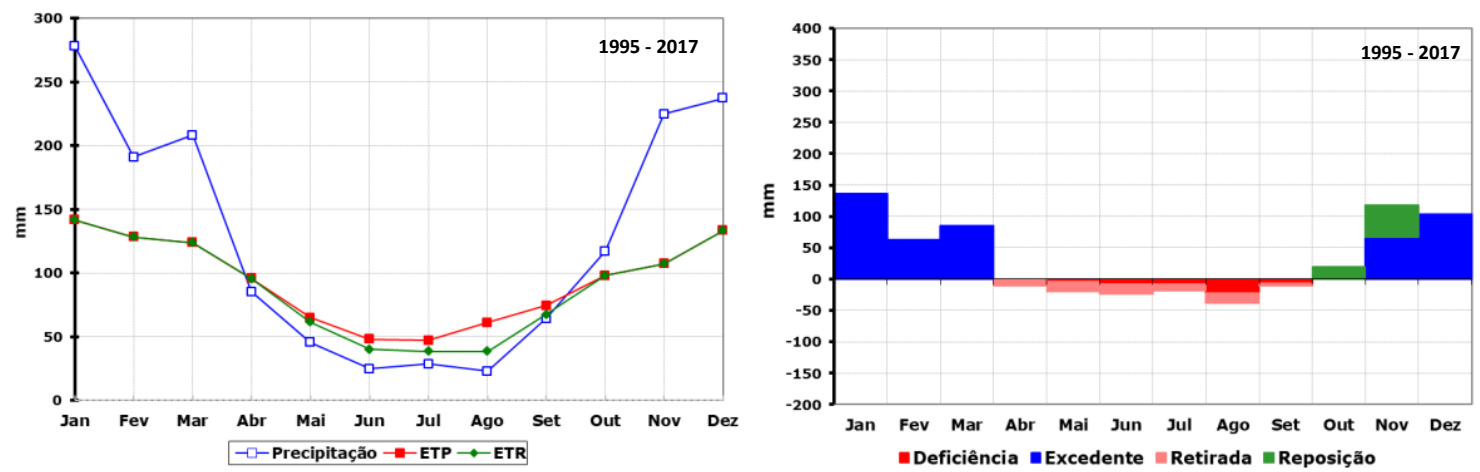

Figura 9 - Balanço hídrico climático para a série histórica em Resende (RJ).

Foram selecionados os anos mais secos e mais chuvosos da série histórica analisada para a aplicação do BHC (Figura 10). O ano de 1999, correspondeu ao mais seco dentre os avaliados, dado o registro de pluviosidade equivalente a $979,5 \mathrm{~mm}$ e total anual inferior de $35,8 \%$ em relação a média da localidade, o que implicou na deficiência hídrica para oito meses (149 mm). O excedente hídrico esteve em apenas $35,3 \mathrm{~mm}$, destacando-se que o mês mais chuvoso para as médias climatológicas. Por outro lado, o mês de janeiro obteve deficiência hídrica de 56,3 mm. O ano de 2017 foi o segundo mais seco 1070,5 $\mathrm{mm}$, aproximadamente $30 \%$ menor que a média anual, com deficiência hídrica constante entre abril e outubro e totais anuais de $111,6 \mathrm{~mm}$ para este parâmetro climático, ao passo que o excedente hídrico foi de $118,1 \mathrm{~mm}$.

O ano de 2008, registrou o segundo maior total de chuva 2053,5 mm e aproximadamente 35\% além da média climatológica, e $1040 \mathrm{~mm}$ deste total precipitado corresponderam ao excedente hídrico. Os maiores excedentes hídricos em 2008 ocorreram nos meses de fevereiro (324,4 mm) e novembro (247,9 mm), sendo que a deficiência hídrica predominou entre maio e setembro, 
e com totais anuais relativamente baixos $(13 \mathrm{~mm})$. O ano mais chuvoso da série em análise foi 2009, com total anual de $2110,2 \mathrm{~mm}$ e $37 \%$ acima da média histórica e, entretanto, registrou menor total anual de excedente hídrico $(976,6$ $\mathrm{mm}$ ) em relação ao ano anterior, com os maiores excedentes em fevereiro (228 $\mathrm{mm}$ ) e dezembro (244 mm). Observou-se que, no ano de 2009, a deficiência hídrica foi abaixo da normalidade $(5,2 \mathrm{~mm})$ e registradas apenas nos meses de abril, maio e agosto (Figura 10).

Dentre os anos mais secos, observa-se que o ano de 1999 esteve em condições da fase La Niña, que atuou de forma duradoura (12 meses) na redução das chuvas, ao passo que o ano de 2017 mostrou a deficiência hídrica esteve associada ao La Niña (entre outubro e dezembro), conforme os dados disponibilizados pelo NOAA (2018). Os anos mais chuvosos da série histórica estiveram em condições parciais de La Niña, sendo em 08 meses para 2008 e 03 meses para 2009, enquanto que a metade final (agosto a dezembro) de 2009 foi caracteriza pela fase El Niño (NOAA, 2018). Desta forma, conforme observado pelos anos selecionados, não é possível estabelecer uma relação direta entre a excedente/deficiência hídrica dos anos mais secos e mais chuvosos da série histórica e as diferentes fases do El Niño-Oscilação Sul (ENOS).
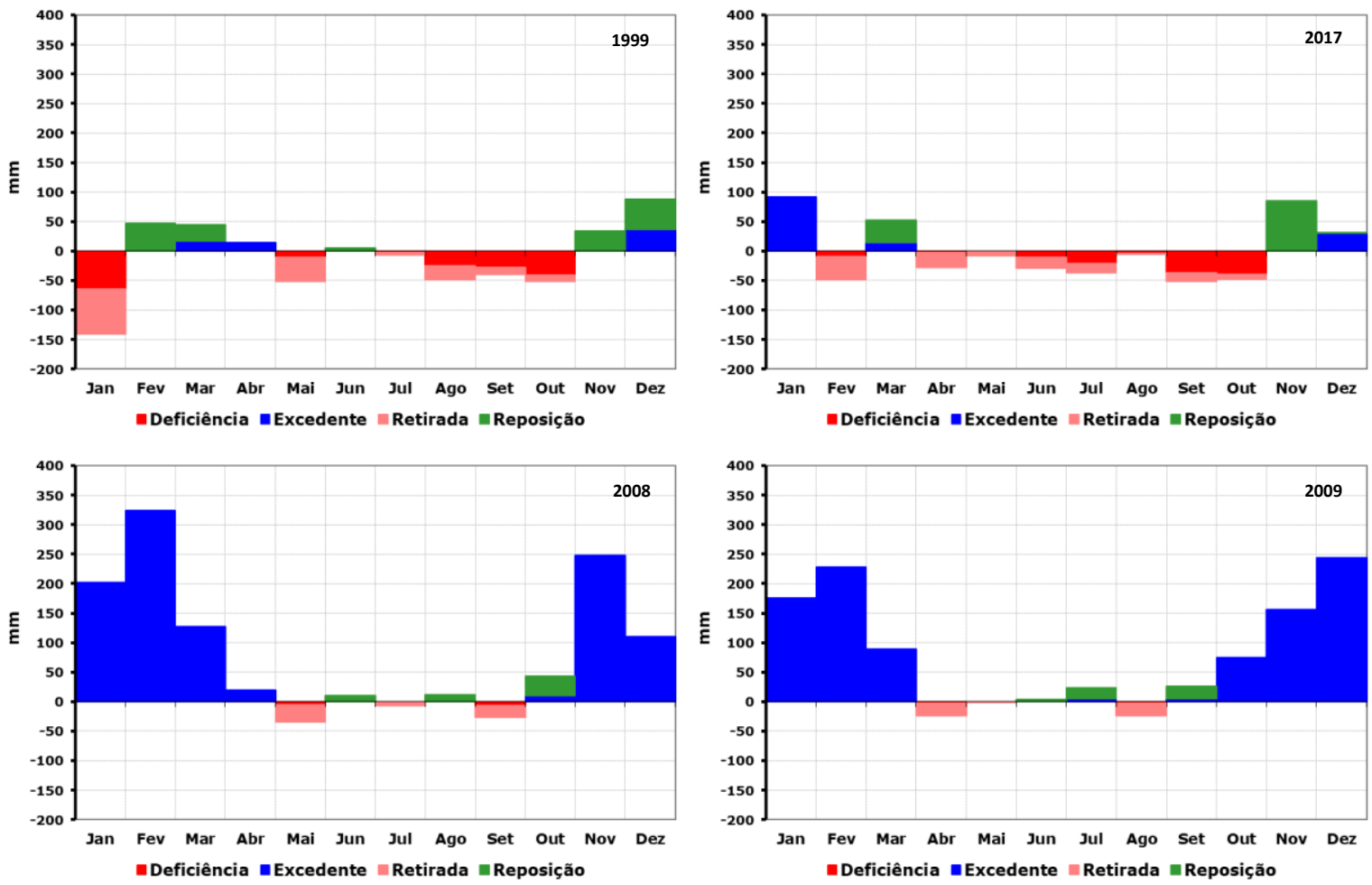

Figura 10 - Balanço hídrico climático para os anos mais secos (1999 e 2017) e mais chuvosos (2008 e 2009) da série histórica em Resende (RJ).

\section{CONSIDERAÇÕES FINAIS}

A estatística descritiva e exploratória da série temporal de chuva em Resende identificou a ocorrência de meses secos entre maio a agosto. Com 
relação ao coeficiente de assimetria é evidente a alta assimetria positiva nas estações seca e úmida, a exceção é o mês de janeiro. A temperatura do ar é registrada assimetria negativa nos meses de maio a agosto, seguida de variações positiva e negativa da assimetria nos meses de setembro a abril. 0 coeficiente $\mathrm{K}$ apresenta um grau de achatamento da curva de distribuição dos dados de chuva e temperatura leptocúrtica $(K>3)$, em junho e julho, e os demais meses com uma curva platicúrtica. E, por fim os CV são altamente variáveis ao longo da série temporal da chuva e temperatura do ar.

A chuva acumulada anual é altamente variável no município de Resende, sendo que anos na série temporal são categorizados como de El Niño Fraco e Moderado, a exceção é La Niña Fraca no ano de 2000. As menores diferenças pluviométricas anuais são nos percentis dos quantis de $25 \%$ e $50 \%$ da média e mediana, seguido das diferenças acima da média, nos percentis de $75 \%$ a $100 \%$ dos quantis. A temperatura anual do ar é altamente variável. Os resultados encontrados estão possivelmente associados às alterações das temperaturas devido ao avanço do processo de remoção da cobertura vegetal nos últimos anos na região. No munícipio é identificado um aumento da temperatura anual correspondente aos percentis dos quantis de $25 \%$ e $50 \%$ da mediana. Entretanto, não há variações na temperatura anual para os percentis acima da média e mediana dos quantis de 75\%, 95\%, 99\% e 100\%.

O balanço hídrico climatológico mostra uma distribuição irregular na chuva mensal na série temporal, com duas estações bem definidas. A estação chuvosa que se inicia em outubro, sendo o maior excedente de chuva em janeiro $(135,6 \mathrm{~mm})$ e em dezembro $(102,9 \mathrm{~mm})$. A estação seca que se inicia em abril e termina no final de agosto, o mês de maior deficiência hídrica para a média climatológica $(19,2 \mathrm{~mm})$.

\section{AGRADECIMENTOS}

O primeiro autor agradece a Coordenação de Aperfeiçoamento de Pessoal de Nível Superior (CAPES) pela concessão da bolsa de Pós-Doutorado PNPD, junto ao Programa de Pós-Graduação em Tecnologia Ambiental (PGTA). O terceiro autor agradece à CAPES pela concessão da bolsa de Doutorado junto ao Programa de Pós-Graduação em Geografia Física da Universidade de São Paulo. Agradecimentos ao Conselho Nacional de Desenvolvimento Científico e Tecnológico pela Bolsa de Produtividade em Pesquisa - nível 2 concedida ao quarto autor (306410/2015-0).

\section{REFERÊNCIAS BIBLIOGRÁFICAS}

ÁLVARES, C.A.; STAPE, J.L.; SENTELHAS, P.C.; DE MORAES GONÇALVES, J.L.; SPAROVEK, G. Köppen's climate classification map for Brazil. Meteorologische Zeitschrift, v.22, n.6, p.711-728, 2013.

ANANIAS, D.S.; SOUZA, E.B.; SOUZA, P.F.S.; SOUZA, A.M.L.; VITORINO, M.I.; TEIXEIRA, G.M.; FERREIRA, D.B. Climatologia da estrutura vertical da atmosfera em novembro para Belém - PA. Revista Brasileira de Meteorologia, São Paulo, v.25, n.2, p.218-226, 2010. 
ANDRÉ, R.G.B.; MARQUES, V.S.; PINHEIRO, F.M.A.; FERRAUDO, A.S. Identificação de regiões pluviometricamente homogêneas no estado do Rio de Janeiro, utilizando-se valores mensais. Revista Brasileira de Meteorologia, São Paulo, v.23, n.4, p.501-509, 2008.

ÁVILA, L. F.; MELLO, C. R.; YANAGI, S. N. M.; SACRAMENTO NETO, O. B. Tendências de temperaturas mínimas e máximas do ar no Estado de Minas Gerais. Pesquisa Agropecuária Brasileira, Brasília, v.49, n.4, p.247-256, 2014.

BRANDÃO, C. B.; SILVA, A.S.; MIRANDA, R.A.C.; GUERRA, A.J.T. A determinação do perfil climatológico do município de Santo Antônio de Pádua-RJ e sua aplicabilidade na recuperação de áreas degradadas. Anuário do Instituto de Geociências - UFRJ, Rio de Janeiro, v.39, n.1, p. 5-12, 2016.

BRITO, T. T.; OLIVEIRA-JÚNIOR, J.F.; LYRA, G.B.; GOIS, G.; ZERI, M. Multivariate analysis applied to monthly rainfall over Rio de Janeiro state, Brazil. Meteorology and Atmospheric Physic, Vienna, v.129, n.5, p.469-478, 2016.

CARVALHO, L.M.V.; JONE, C.; LIEBMANN, B. Extreme Precipitation Events in Southeastern South America and Large-Scale Convective Patterns in the South Atlantic Convergence Zone. Journal of Climate, Boston, v.15, n.17, p.23772394, 2002.

CEPERJ (Centro estadual de estatísticas, pesquisas e formação de servidores públicos do estado do Rio de Janeiro). Divisão regional, segundo as mesorregiões, microrregiões geográficas e municípios, Estado do Rio de Janeiro. 2018. Disponível em: <www.ceperj.rj.gov.

CIRINO, G.G.; SOUZA, R.A.F.; ADAMS, D.K.; ARTAXO, P. The effect of atmospheric aerosol particles and clouds on net ecosystem exchange in the Amazon. Atmospheric Chemistry and Physics, London, v.14, n.3, p.6523-6543, 2014.

COSTA, A. O.; SALGADO, C.M.; DIANALI, Y.T. Caracterização da precipitação no médio vale do rio Paraíba do Sul Fluminense (RJ). Revista Geonorte, Manaus, v.3, n.9, p. 1000-1013, 2012.

DUBREUIL, V.; FANTE, K.P.; PLACHON, O.; SANT'ANNA NETO, J.L. Les types de climats annuels au Brésil: une application de la classification de Köppen de 1961 à 2015. EchoGéo, v.3, n.41, p.1-27, 2017.

FARIAS, O. G.; FRANCISCO, C. N.; SENNA, M.C.A. Avaliação de métodos de interpolação espacial aplicados à pluviosidade em região montanhosa no litoral sul do estado do Rio de Janeiro. Revista Brasileira de Climatologia, Curitiba, v.21, n. 13, p. 172-185, 2017.

FIETZ, C. R.; URCHEI, M. A.; FRIZZONE, J. A. Probabilidade de ocorrência de déficit hídrico na região de Dourados, MS. Revista Brasileira de Engenharia Agrícola e Ambiental, Campina Grande, v.5, n.3, p.558-562, 2001.

FIGUEIRÓ, A. S.; COELHO NETTO, A. L. Climatic variability and pluviometric trends in a humid tropical environment at Resende municipality- middle Paraíba do Sul river valley (Rio de Janeiro- Brazil). Geographical Journal: Geosciences and Humanities research medium, v.2, n.2, p.256-273, 2011. 
GAMA BENTES, J.C. A transformação dos ambientes natural e rural com a industrialização do Médio Paraíba do Sul, RJ. In: V Encontro Nacional da ANPPAS, Florianópolis, p.503-508. 2010.

IBGE - Instituto Brasileiro de Geografia e Estatística. Disponível em < IBGE, https://www.ibge.gov.br/geociencias-novoportal/cartas-e-mapas/redesgeograficas/15778-divisoes-regionais-do-brasil.html $?=\& \mathrm{t}=$ acesso-ao-produto $>$. Acessado em 20 de maio de 2018.

KELLER FILHO, T; ASSAD, E.D.; LIMA, P.R.S.R. Regiões pluviometricamente homogêneas no Brasil. Pesquisa Agropecuária Brasileira, Brasília, v.40, n.4, p.311-322, 2005.

KODAMA, Y. M. Large-scale common features of subtropical precipitation zones (the Baiu frontal zone, the SPCZ, and the SACZ), Part I: Characteristics of subtropical frontal zones. Journal of the Meteorological Society of Japan, Tokyo, v.70, n.4, p.813-835, 1993.

KÖPPEN, W. Climatologia: con un estudio de los climas de la tierra. Fondo de Cultura Econômica. México. 1948. 479p.

LO PRESTI, R.; BARCA, E.; PASSARELLA, G. A methodology for treating missing data applied to daily rainfall data in the Candelaro River Basin (Italy). Environmental Monitoring and Assessment, Londres, v.160, n.4, p.1-22, 2010.

MACHIWAL, D.; KUMAR, S.; DAYAL, D. Characterizing rainfall of hot arid region by using time-series modeling and sustainability approaches: a case study from Gujarat, India. Theoretical and Applied Climatology, Berlim, v.124, n.3-4, p.593-607, 2015.

MELLO, C. R.; SILVA, A. M. Modelagem estatística da precipitação mensal e anual e no período seco para o estado de Minas Gerais. Revista Brasileira de Engenharia Agrícola e Ambiental v.13, n.1, p.68-74, 2009.

MINUZZI, R. B. Tendências na variabilidade climática de Santa Catarina, Brasil. Revista Brasileira de Engenharia Agrícola e Ambiental, Campina Grande, v.14, n.12, p.1288-1293, 2010.

MINUZZI, R. B.; CARAMORI, H.; BORROZINO, E. Tendências na variabilidade climática sazonal e anual das temperaturas máxima e mínima do ar no Estado do Paraná. Bragantia, Campinas, v.70, n.2, 2011, p. 471-479.

NERY, J. T.; MARTINS, M. L. F.; SANTANNA NETO, J. L. Variabilidade da Precipitação no Brasil Meridional. Acta Scientiarum Technology (UEM), Maringá, v.24, n.6, p.1687-1695, 2002.

NOAA (National Oceanic and Atmospheric Administration). 2018. Disponível em: http://www.c

pc.ncep.noaa.gov/products/analysis_monitoring/ensostuff/ensoyears.shtml. Acesso em 17 de setembro de 2018.

PEREIRA, A.R. Simplificando o Balanço Hídrico de Thornthwaite - Mather. Bragantia, Campinas, v.64, n.2, p.311-313, 2005.

R Development Core Team, 2017. R: A language and environment for statistical computing. $\mathrm{R}$ Foundation for Statistical Computing, Vienna, Austria, http://www.r-project.org, ISBN 3-900051-07-0 
REBOITA, M.S.; GAN, M.A.; ROCHA, R.P.; AMBRIZZI, T. Regimes de precipitação na América do Sul. Revista Brasileira de Meteorologia, São Paulo, v.25, n.2, p.185-204, 2010.

ROLIM, G. S., SENTELHAS, P. C. Balanço Hídrico Normal por Thornthwaite \& Mather (1955). Piracicaba. ESALQ. 1999. CD-ROM.

ROLIM, G. S.; SENTELHAS, P. C.; BARBIERI, V. Planilhas no ambiente EXCEL para os cálculos de balanços hídricos: normal, sequencial, de cultura e de produtividade real e potencial. Revista Brasileira de Agrometeorologia, Santa Maria, v.6, n.1, p.133-137, 1998.

ROLIM, G.S.; CAMARGO, M.B.P.; LANIA, D.G.; MORAES, J.F.L. Classificação climática de Köppen e de Thornthwaite e sua aplicabilidade na determinação de zonas agroclimáticas para o estado de São Paulo. Bragantia, Campinas, v.66, n.4, p.257-533, 2007.

SALTON, F. G.; MORAIS, H.; CARAMORI, H.; BORROZZINO, E. Climatologia dos episódios de precipitação em três localidades no estado do Paraná. Revista Brasileira de Meteorologia, São Paulo, v. 31, n. 4, 626-638, 2016.

SANT'ANNA NETO, J.L. Dinâmica Atmosférica e o caráter transicional do clima na Zona Costeira Paulista. Revista do Departamento de Geografia (USP), São Paulo, v.8, n.1, p.35-49, 1994.

SANTOS, A.P.P.; ARAGÃO, M.R.S.; CORREIA, M.F.; SANTOS, S.R.Q.; SILVA, F.D.S.; ARAÚJO, H.A. Precipitação na cidade de Salvador: variabilidade temporal e classificação em Quantis. Revista Brasileira de Meteorologia, São Paulo, v.31, n.4, p.1-14, 2016.

SANTOS, A.P.P.; ARAGÃO, M.R.S.; SOUZA, J.R.S.; SANTOS, S.R.Q.; LINDEMANN, D.S. Aplicação da técnica dos quantis à precipitação no Leste da Amazônia e suas relações com o fenômeno ENOS no Período 1998 - 2008. In: IV Simpósio Internacional de Climatologia, João Pessoa, p.1-5, 2011.

SILVA, C.B.; SANT'ANNA NETO, J.L.; TOMMASELLI, J.T.G.; PASSOS, M.M. Dinâmica atmosférica e análise geoestatística do clima na área de integração paisagística 'Raia Divisória' SP/PR/MS: uma proposta de tipologia climática. Revista Brasileira de Climatologia, Curitiba, v.2, n.1, p. 53-70, 2006.

SILVA, W. L.; DERECZYNSKI, C. P. Caracterização Climatológica e Tendências Observadas em Extremos Climáticos no Estado do Rio de Janeiro. Anuário do Instituto de Geociências UFRJ, Rio de Janeiro, v.37, n.2, p.123-138, 2014.

SOBRAL, B.S.; OLIVEIRA JÚNIOR, J.F.; GOIS, G.; TERASSI, P.M.B.; MUNIZ JUNIOR, J.G.R. Variabilidade espaço-temporal e anual da chuva no estado do Rio de Janeiro. Revista Brasileira de Climatologia, Curitiba, v.22, n.1, p.281308, 2018.

SOUZA, W.M.; AZEVEDO, P.V.; ARAÚJO, L.E. Classificação da precipitação diária e impactos decorrentes dos desastres associados às chuvas na cidade do Recife - PE. Revista Brasileira de Geografia Física, Recife, v.5, n.2, p.250-268, 2012.

THORNTHWAITE, C.W. An approach towards a rational classification of climate. Geographycal Review London, Nova Jersey, n. 38, p. 55-94, 1948.

THORNTHWAITE, C.W.; MATHER, J.R. The water balance climatology. Centerion, v.8, n.1, p. 1-86,1955. 
XAVIER, T.M.B.S.; XAVIER, A.F.S. Caracterização de períodos secos ou excessivamente chuvosos no estado do Ceará através da técnica dos Quantis: 1964-1998. Revista Brasileira de Meteorologia, São Paulo, v.14, n.2, p. 63-78, 1999.

XAVIER, T.M.B.S.; XAVIER, A.F.S. Classificação e monitoração de períodos secos e chuvosos e cálculo de índices pluviométricos para a região Nordeste do Brasil. Revista Brasileira de Engenharia/Cadernos de Recursos Hídricos, Porto Alegre, v.5, n.2, p.7-31, 1987.

ZANDONADI, L.; ACQUAOTTA, F.; FRATIANNI, S.; ZAVATTINI, J. A. Changes in precipitation extremes in Brazil (Paraná River Basin). Theoretical and Applied Climatology, Berlim, v.119, n.1, p. 741-756, 2015. 